\title{
5. Politiques intérieure et extérieure
}

Xavier Tschumi Canosa, Laurent Goetschel, Daniel Schwarz, Gérard Perroulaz, Rosita Fibbi et Michael Cottier

\section{(2) OpenEdition}

\section{Journals}

Édition électronique

URL : http://journals.openedition.org/aspd/944

DOI : 10.4000/aspd.944

ISSN : 1663-9669

Éditeur

Institut de hautes études internationales et du développement

Édition imprimée

Date de publication : 1 avril 2002

Pagination : 207-254

ISSN : 1660-5934

\section{Référence électronique}

Xavier Tschumi Canosa, Laurent Goetschel, Daniel Schwarz, Gérard Perroulaz, Rosita Fibbi et Michael Cottier, « 5. Politiques intérieure et extérieure », Annuaire suisse de politique de développement [En ligne], 21 | 2002, mis en ligne le 06 septembre 2012, consulté le 07 septembre 2020. URL : http:// journals.openedition.org/aspd/944; DOI : https://doi.org/10.4000/aspd.944 


\section{POLITIQUES INTÉRIEURE ET EXTÉRIEURE*}

\subsection{LA SUISSE ET L'ONU}

Suite au message du Conseil fédéral relatif à l'initiative pour l'adhésion de la Suisse à l'ONU, du 4 décembre 2000, les deux Chambres fédérales ont chacune, avec une large majorité et sans contre-projet, recommandé au peuple suisse de voter en faveur de l'adhésion le 3 mars 2002. Le Conseil fédéral ne ménage pas ses efforts pour soutenir cette adhésion. La question de la neutralité helvétique a été au centre des débats et figurera explicitement sous forme de déclaration dans la demande d'adhésion que la Suisse déposera auprès de l'ONU, en cas de succès de l'initiative.

\subsubsection{BREF RAPPEL HISTORIQUE}

Depuis que le peuple et les cantons suisses l'avaient massivement ${ }^{1}$ refusée en votation populaire, le 16 mars 1986, l'adhésion de la Suisse à l'ONU revient avec beaucoup de force sur le devant de la scène politique, notamment après le dépôt d'une initiative populaire en ce sens (mars 2000) et le message du Conseil fédéral concernant cette initiative (décembre 2000).

Le Conseil fédéral a fait de cette question d'adhésion l'un des objectifs prioritaires de son programme de législature 1999-2003 et recommande donc au peuple suisse d'accepter l'initiative "pour l'adhésion de la Suisse à l'Organisation des Nations Unies ».

凹 ASTM 2001, pp. 245-248.

\subsubsection{ENGAGEMENT DU CONSEIL FÉDÉRAL EN FAVEUR DE L'ADHÉSION DE LA SUISSE Ȧ L'ONU}

En mars 2001, la Division politique III (section ONU) du Département fédéral des affaires étrangères (DFAE) a publié une brochure ${ }^{2}$ qui reprend, sous une forme didactique, les arguments développés par le Conseil fédéral dans son message relatif à l'initiative pour l'adhésion de la Suisse à l'ONU.

* Parties 5.1. et 5.5. : par Xavier Tschumi, licencié en économie et diplômé de l'IUED, Genève.

Partie 5.2. : par Laurent Goetschel, directeur de la Fondation suisse pour la paix, professeur de politique européenne à l'institut européen de l'Université de Bâle, chargé de cours de politique extérieure suisse à l'Université de Berne; et Daniel Schwarz, politologue et collaborateur scientifique à la Fondation suisse pour la paix, Berne.

Partie 5.3.: par Gérard Perroulaz, chargé de recherche à l'IUED, Genève.

Partie 5.4. : par Rosita Fibbi, sociologue, Institut d'anthropologie et de sociologie, Université de Lausanne; Forum suisse pour l'étude des migrations, Université de Neuchâtel.

Partie 5.6. : par Michael Cottier, doctorant en droit international à l'Université de Fribourg; diplôme postgrade LLM (New York University Law School).

1. L'entrée de la Suisse à l'ONU avait été refusée par $75 \%$ des voix et par la totalité des cantons.

2. DFAE, La Suisse et l'ONU, une information du Département fédéral des affaires étrangères DFAE, mars 2001. Cette brochure peut être commandée par téléphone (031/325 50 50), par fax (031/325 50 58) ou par Internet: <www.bbl.admin.ch>, numéro de commande $201.250 \mathrm{f}$. 
Pour commencer, cette brochure résume l'histoire de l'ONU, puis examine le rôle de cette organisation face aux nouveaux défis, notamment dans le cadre du maintien de la paix. Ensuite, elle met en exergue les buts communs de la Suisse et de l'ONU: pour un monde sans guerre, sans oppression, sans faim ni misère et enfin sans atteinte à l'environnement. La brochure poursuit la concentration de ses propos en décrivant d'abord la situation actuelle de la Suisse par rapport à l'ONU (le statut d'observateur de la Suisse à l'ONU, la Suisse en tant que pays hôte de l'ONU et les retombées économiques favorables à la Suisse des activités de l'ONU) pour arriver enfin à la question de l'adhésion de la Suisse à l'ONU, qui soulève celle de la neutralité helvétique et celle des coûts de l'adhésion.

Le DFAE, en collaboration avec le Centre d'analyse et de prospective (CAP, Berne), a également publié, en mai 2001, un dossier spécial consacré à la Suisse et l'ONU, dans sa revue trimestrielle de politique étrangère Politorbis ${ }^{3}$. Ce document comprend 11 textes courts, signés par différentes personnalités de l'Administration fédérale suisse et du milieu académique suisse, ainsi que par des fonctionnaires étrangers. Ces textes portent surtout sur l'ONU, bien que dans l'introduction à ce dossier, le secrétaire d'Etat du DFAE milite explicitement en faveur de l'adhésion de la Suisse à l'ONU.

Indice supplémentaire de l'engagement du Conseil fédéral en faveur de l'adhésion, ce sont cinq conseillers fédéraux qui ont reçu Kofi Annan en mars 2001, lorsque ce dernier a visité la Suisse et a déclaré qu'il l'attendait les bras ouverts au sein de son organisation.

\subsubsection{TRAVAIL DES COMMISSIONS ET DÉBAT AUX CHAMBRES FÉDÉRALES}

Avant la votation fédérale, qui se tiendra le 3 mars 2002, la question de l'adhésion de la Suisse à l'ONU a d'abord été examinée par la Commission de politique extérieure du Conseil des Etats (CPE-CE), en mai 2001. Le vote final a montré un soutien à l'initiative de 10 contre 1 . Le 21 juin 2001, le Conseil des Etats se prononçait également en faveur de l'initiative, par 37 voix contre 2 (UDC).

Le 28 juin 2001, la campagne pour l'adhésion de la Suisse à l'ONU a été lancée par le groupe d'information Suisse-ONU, emmené par la conseillère aux Etats radicale bernoise Christine Beerli. Ce groupe est une coalition gauche-droite, composée de politiciens, de diplomates, de représentants de l'économie et des Eglises, ainsi que de personnalités publiques suisses.

Le 10 août 2001, l'UDC a lancé son contre-projet à l'initiative populaire, soit quelques jours avant que la Commission de politique extérieure du Conseil national (CPE-CN) n'examine la question. Ce contre-projet part de la conception selon laquelle l'obligation constitutionnelle qu'a la Suisse de préserver son indépendance et sa neutralité empêche ce pays de devenir membre à part entière d'une organisation internationale (de l'ONU en particulier). Si le Parlement devait refuser ce contre-projet, l'UDC a proposé subsidiairement que l'adhésion de la Suisse à l'ONU soit alors assortie d'une authentique réserve de neutralité, confirmée par l'ONU avant l'entrée de la Suisse dans cette organisation. Le 14 août 2001, la CPE-CN a balayé ce contre-projet en soutenant l'initiative par 18 voix contre 4 (UDC).

3. DFAE et CAP, «Dossier: La Suisse et l'ONU», Politorbis, édition spéciale d'avril 2001. 
En plénum, le 19 septembre 2001, le Conseil national a suivi l'avis de sa commission, en recommandant au peuple suisse de voter oui à l'initiative populaire pour l'adhésion de la Suisse à l'ONU (151 voix pour, 44 voix contre).

L'initiative populaire pour l'adhésion de la Suisse à l'ONU ira donc sans contreprojet en votation populaire.

\subsubsection{LA QUESTION DE LA NEUTRALITÉ HELVÉTIQUE DANS LE DÉBAT SUR L'ADHÉSION}

Dans son message relatif à l'initiative pour l'adhésion de la Suisse à l'ONU, et depuis lors, le Conseil fédéral a toujours soutenu que cette adhésion ne remettait pas en question la politique de neutralité de la Suisse. Au cours des débats parlementaires, notamment au Conseil des Etats, la grande majorité des intervenants (y compris Joseph Deiss, le chef du DFAE) préconisait que la Suisse devait assortir sa demande d'adhésion d'une déclaration dans laquelle elle définirait elle-même sa neutralité et les limites que celle-ci impliquait. La Suisse adhérerait alors à l'ONU comme un Etat neutre, qui est un statut reconnu par cette organisation et, en tant qu'Etat neutre, la Suisse ne serait alors pas obligée de s'associer aux sanctions économiques et/ou militaires décidées par le Conseil de sécurité de l'ONU.

Dans une recommandation ${ }^{4}$, un conseiller aux Etats a pourtant demandé au Conseil fédéral de s'assurer que l'ONU accepte la réserve de neutralité helvétique avant la votation populaire, en l'absence d'un contre-projet à l'initiative qui aurait pu permettre de compléter l'arrêté fédéral soumis au vote. Dans sa prise de position (22 août 2001), le Conseil fédéral explique qu'il n'est pas acceptable de demander à l'ONU de débattre de la neutralité de la Suisse avant que ce pays n'adhère à cette organisation et que l'usage d'une réserve, au sens juridique, enverrait le signal que la Suisse ne serait pas capable de remplir l'ensemble des obligations de la Charte des Nations Unies, alors que c'est sans restriction qu'elle pourrait se conformer à ce texte.

Pour lever toute équivoque, le Conseil fédéral a rendu public, le 24 octobre 2001, le texte de la demande d'adhésion de la Suisse à l'ONU, incluant une déclaration relative à la neutralité. Cette déclaration mentionne explicitement qu'«en tant que membre de l'Organisation des Nations Unies, la Suisse restera neutre $»^{5}$.

\section{SOURCES}

Dossier du Parlement fédéral sur la Suisse et l'ONU : <www.parlement.ch/F/UNO/UNO_f.htm>.

Dossier du Département fédéral des affaires étrangères sur la Suisse et l'ONU: <www.eda.admin.ch/ sub_uno/f/uno/chun.html>.

Groupe d'information Suisse-ONU: <www.suisse-onu.ch>.

4. Recommandation Christoffel Brändli, «Préserver la neutralité de la Suisse en cas d'adhésion à l'ONU», 01.3335, 20.6.01.

5. «Avant le vote sur l'ONU, le Gouvernement affiche son attachement à la neutralité », Le Temps, 25.10.01. 


\subsection{POLITIQUE EN MATIÈRE DE SÉCURITÉ ET POLITIQUE DE PAIX DE LA SUISSE EN 2001}

\subsubsection{INTRODUCTION ET STATISTIQUES}

L'année 2001 a été plutôt mouvementées pour la politique suisse de sécurité et de la paix. En marge d'une situation internationale agitée, la Suisse a traversé une période de changements dans ces deux domaines: le DFAE a étendu ses compétences dans le domaine de la promotion de la paix et obtenu des ressources supplémentaires pour renforcer la coopération avec des partenaires extérieurs à l'administration. Le DDPS a poursuivi l'élaboration du Plan directeur de l'armée et a passé, de justesse, un test extrêmement important: le vote concernant l'envoi de soldats suisses armés à l'étranger dans le cadre d'interventions internationales pour la promotion de la paix. D'autres échéances étant d'ores et déjà prévues, l'effervescence qui caractérise en ce moment les relations extérieures de la Suisse ne risque guère de retomber.

\section{$\square$ Dépenses militaires et exportations d'armement}

Depuis 1998, les dépenses militaires et d'armement sont à nouveau en hausse dans le monde entier. Pendant la seule période 1999-2000, elles ont enregistré une augmentation de $3 \%(+0,3 \% \text { en Suisse })^{6}$. Cette tendance se retrouve dans toutes les régions du monde, quoique l'Afrique enregistre depuis 1998 la hausse la plus forte, avec $37 \%$, suivie par l'Asie du Sud (+ 23\%). Dans ces deux régions, ce sont de nouveaux conflits ou des guerres déjà en cours qui ont renforcé l'armement.

Par ailleurs, les Etats-Unis, la Russie et l'Europe ont également nettement accru leurs dépenses militaires et prévoient que cette hausse se poursuivra dans les années à venir. Le débat sur les mesures contre le terrorisme international, qui a été relancé récemment, incitera sans doute aussi les Etats à gonfler leurs budgets militaires pour accroître le sentiment de sécurité subjectif au sein de leurs populations.

En 2000, les exportations suisses de matériel de guerre se montaient encore à 213,6 millions de francs, ce qui correspond à peu de chose près à leur valeur de 1998 et dénote un recul de plus de $7 \%$ par rapport à $1999^{7}$. La part du matériel de guerre dans l'ensemble des exportations suisses d'armement demeure donc à $0,16 \%$ et ne représente qu'une quantité négligeable. Les principaux acheteurs d'armement suisse ont été l'Allemagne, les Etats-Unis, le Canada, la Roumanie et l'Argentine. Dans certains cas, les exportations d'armes étaient destinées à des pays où se déroulent des conflits armés importants, selon la définition du SIPRI (Philippines, Pakistan et Soudan). Selon les statistiques, il s'agit d'exportations d'armes de poing et d'autres armes, également classées dans la catégorie des armes légères ou de petit calibre (voir ci-dessous, sous-chap. 5.2.3, point "Armes légères et de petit calibre»). Quant à leur prix, ces exportations ne représentent toutefois que $0,15 \%$ du total des exportations de matériel de guerre.

6. Voir SIPRI Yearbook 2001: Armaments, Disarmament and International Security, pp. 223 sqq.; Département fédéral des finances, Les finances de la Confédération en bref. Budget 2002, Berne, 2002.

7. Voir Seco, communiqué de presse, 6.2.01. 


\subsubsection{POLITIQUE DE LA PAIX}

\section{$\square$ Fondation du Centre pour la promotion de la paix}

Le Centre pour la promotion de la paix (KOFF - Kompetenzzentrum Friedensdörderung) a été fondé en mars 2001 dans le cadre de la Fondation suisse pour la paix (FSP). Appuyé par le DFAE et nombre d'organisations non gouvernementales suisses (ONG), le centre a pour but de soutenir le rôle constructif de la Suisse lors du règlement de conflits internationaux. Pour jouer ce rôle, la Suisse doit se doter d'une politique de paix cohérente. Le centre souhaite contribuer à cette cohérence, d'une part en créant des synergies entre les divers acteurs, étatiques ou non étatiques, nationaux ou internationaux, de la promotion de la paix. D'autre part, le centre favorise la cohérence dans la conception et dans l'application de la politique de paix suisse en réalisant des analyses, en proposant des conseils et des cours, ainsi que par la création de réseaux. Ses travaux concernent toutes les phases d'un conflit (prévention, gestion du conflit et période postconflit).

La direction stratégique du centre est assurée par un comité de direction qui réunit deux représentants de la Direction politique du DFAE, un représentant de la Direction du développement et de la coopération (DDC), trois représentants d'ONG suisses et le directeur de la FSP. Au cours de ses premiers six mois d'existence, le centre a notamment créé trois groupes de travail permanents centrés sur un pays ou sur un thème spécifique. L'un de ces groupes est chargé d'étudier les corrélations entre la coopération au développement, l'aide humanitaire et la promotion de la paix. Le centre publie chaque mois une newsletter en allemand, en anglais et en français. Au cours de cette période, le DFAE et les responsables d'ONG ont déjà fait appel au centre pour requérir les services suivants: analyse de conflit, développement de programmes et de projets, évaluation, échanges d'expériences et formation ${ }^{8}$.

\section{- Réorganisation et renforcement des compétences} au sein de la Direction politique du DFAE

$\mathrm{Au}$ sein de sa Direction politique, le DFAE a réorganisé en 2001 la division chargée de la politique de sécurité et de la paix : la Division politique IV, compétente à l'origine uniquement en matière de droits de l'homme, a changé de nom pour devenir la division «Sécurité humaine (paix, droits de l'homme, politique humanitaire)». Ses effectifs ont été accrus et elle comprend désormais les sections suivantes: «Politique de paix et sécurité humaine», «Politique des droits de l'homme», «Politique humanitaire et migration» et «Opérations et pool d'experts pour la promotion civile de la paix ». Cette dernière section comprend également l'administration du «Pool d'experts pour la promotion civile de la paix », créé en été 2001. Le pool regroupe les observateurs électoraux, les experts en matière de droits de l'homme, ainsi que d'autres catégories de fonctions prenant part à des missions de l'OSCE ou de 1'ONU. Ses membres ont suivi un premier module de formation de deux semaines en octobre 2001. Dans sa nouvelle structure, la division comprend même un ambassadeur en mission spéciale dans le domaine de la gestion des conflits, qui est chargé d'évaluer la

8. De plus amples informations ainsi que les newsletters se trouvent sur le site <www.swisspeace.ch>. 
situation dans certaines régions en conflit et de décider de la participation de la Suisse à des processus de paix.

Dans le domaine de la politique de sécurité, une nouvelle unité a été créée: il s'agit du Centre pour la politique de sécurité internationale. A l'instar du Centre d'études d'analyse prospective, ce nouveau centre est directement soumis au secrétaire d'Etat. Il sera chargé d'étudier des thèmes concernant le Partenariat pour la paix de 1'OTAN, le Conseil du partenariat euro-atlantique (CPEA) et la politique extérieure et de sécurité commune de 1'Union européenne. Il devra également renforcer la présence du DFAE dans ces domaines.

\section{$\square$ Priorités géographiques et thématiques de la politique suisse de la paix}

Dans le nouveau Rapport sur la politique extérieure, adopté à la fin de 2000, le Conseil fédéral se donne pour objectif de contribuer de manière sensible et visible aux efforts de paix dans le monde. Le rapport indique par ailleurs que la politique suisse de la paix se concentrera en priorité sur les régions géographiques suivantes: Europe du Sud-Est, Europe de l'Est et région méditerranéenne. Du point de vue thématique, le Conseil fédéral concentrera d'une part ses efforts sur des activités de médiation et visant à établir la confiance; dans le cadre de la coopération au développement, il entreprendra d'autre part des actions de promotion de la paix, avant tout dans les domaines suivants:

口 promotion d'efforts locaux en faveur de la paix, promotion de la reconstruction et de la réinsertion;

口 renforcement de la société civile et du dialogue entre Etat et société civile;

口 appui à diverses formes de médiation impartiales ;

- promotion de la compréhension mutuelle et de la transparence dans les situations de conflit ${ }^{9}$.

Le Conseil fédéral entend par ailleurs accorder une attention particulière aux mesures en faveur de la sécurité humaine.

\subsubsection{SÉCURITÉ HUMAINE}

La notion de «sécurité humaine» a été utilisée pour la première fois par la Commission on Global Governance dans son rapport sur «notre voisinage mondial» $(1995)^{10}$. Cette notion désigne la sécurité de l'individu, qui devrait pouvoir vivre partout dans le monde sans subir d'atteinte à son intégrité corporelle, sans crainte et sans être soumis à des décisions arbitraires. Les domaines que recouvre la notion de «sécurité humaine» ne sont en réalité guère nouveaux: il s'agit pour l'essentiel des droits de l'homme, du droit international humanitaire, de la juridiction pénale internationale ainsi que des efforts accomplis pour lutter contre la prolifération de mines et d'armes de petit calibre, ainsi que contre l'enrôlement d'enfants dans l'armée. Le rapprochement de domaines, que l'étude et les points de vue séparent souvent, souligne cependant la dimension humaine ou individuelle.

9. Rapport sur la politique extérieure 2000. Présence et coopération: la sauvegarde des intérêts dans un monde en cours d'intégration du 15 novembre 2000, Feuille fédérale 2001, pp. 277-278.

10. Our Global Neighborhood. Report of the Commission on Global Governance, Oxford: Oxford University Press, 1995, pp. 79-82. 


\section{$\square$ Armes légères et de petit calibre}

L'expression «armes de petit calibre et armes légères» désigne des armes conventionnelles, qui peuvent être transportées ou utilisées par une seule ou plusieurs personnes ${ }^{11}$. La plupart des conflits qui ont éclaté depuis la fin de la guerre froide ont été presque exclusivement menés au moyen de ces armes de petit calibre. Les efforts consentis dans ce domaine visent donc essentiellement à lutter contre la prolifération de ces armes et contre leur usage abusif.

La Suisse œuvre depuis plusieurs années déjà au contrôle des armes légères et de petit calibre, en particulier pour ce qui est des points suivants: techniques de marquage, développement de critères pour la fabrication, transfert d'armes de petit calibre, ainsi que gestion et sécurité d'arsenaux.

Concernant le marquage et le pistage d'armes légères, la Suisse a soumis, avec la France, une initiative à la Conférence des Nations Unies sur les armes légères, tenue en juillet 2001, qui se fonde essentiellement sur les aspects préventifs, sur l'engagement des Etats à coopérer et sur des critères d'application clairement définis. En bref, cette initiative propose l'élaboration d'un instrument international qui permettrait de pister les armes légères grâce à leur marquage uniformisé, à leur répertoriage et à un échange d'informations au niveau international ${ }^{12}$. A l'occasion de la Conférence sur les armes légères, la Suisse a également présenté la première édition du Small Arms Survey ${ }^{13}$. Il s'agit de l'annuaire d'un projet qui porte le même nom et qui est domicilié auprès de l'Institut universitaire de hautes études internationales (IUHEI) à Genève. Ce projet, financé pour l'essentiel par la Direction politique du DFAE, s'est donné pour objectif de faire régner un peu plus de transparence dans le domaine des armes légères.

\section{$\square$ Mines antipersonnel}

La Suisse a compté parmi les premiers Etats signataires de la Convention de décembre 1997 sur l'interdiction de l'emploi, du stockage, de la production et du transfert des mines antipersonnel et sur leur destruction, et elle a ratifié cette convention l'année suivante. Au sein de l'administration fédérale, c'est la Direction politique du DFAE qui coordonne les activités de la Suisse dans le domaine des mines antipersonnel. Ces activités comprennent le financement et

11. Selon la définition de l'ONU de 1997 (Doc. A/52/298) et selon un document de 2000 de l'OSCE sur les armes de petit calibre et sur les armes légères, les armes de petit calibre sont les suivantes: revolvers et pistolets à chargement automatique; fusils et carabines; mitraillettes; fusils d'assaut et mitrailleuses légères. Quant aux armes légères, les voici : mitrailleuses lourdes; lance-grenades portatifs, amovibles ou montés; canons antiaériens portatifs; canons antichars portatifs, fusils sans recul; lance-missiles et lance-roquettes antichars portatifs; lance-missiles antiaériens portatifs; mortiers de calibre inférieur à 100 millimètres; munitions et explosifs, tels que cartouches, munitions pour armes de petit calibre; projectiles et missiles pour armes légères; conteneurs mobiles avec missiles ou projectiles pour systèmes antiaériens ou antichars à simple action; grenades à main antipersonnel et antichars; mines terrestres et explosifs.

12. DFAE, communiqué de presse, 27.6.01. Voir aussi : Comité préparatoire de la conférence des Nations Unies sur le commerce illicite des armes légères sous tous ses aspects, Document de travail présenté par la Suisse et la France sur la mise en place d'un dispositif de traçage pour la prévention et la réduction de l'accumulation et du transfert excessif et déstabilisateur d'armes légères, janvier 2001 (A/CONF.192/PC/25).

13. Small Arms Survey, Small Arms Survey. Annuaire sur les armes légères et de petit calibre 2001. Gros plan sur les armes légères, Oxford: Oxford University Press, 2001, <www.smallarmssurvey.org>. 
la prise en charge de projets de déminage dans certains pays, des projets principalement axés sur 1'Europe du Sud-Est et sur le Mozambique. C'est dans ce dernier pays que la Suisse mène le projet le plus vaste et à très long terme, en étroite collaboration avec la DDC et le DDPS. D'ici à la fin de 2002, le DDPS mettra par ailleurs sur pied une équipe de 40 experts du déminage pour assurer les interventions internationales.

\section{$\square$ Séminaire de l'OSCE sur la sécurité écologique}

Sur une initiative de la Suisse et de l'Allemagne, l'OSCE a tenu à Berlin, en juillet 2001, un «Séminaire sur le renforcement du rôle de l'OSCE dans le domaine de l'environnement et de la sécurité». Cette réunion avait pour objectif de trouver des moyens de renforcer le rôle de l'OSCE dans la prévention de conflits en rapport avec des problèmes écologiques et elle s'est notamment penchée sur un projet de la Suisse visant à élaborer un code de conduite spécifique. Au terme du séminaire, les participants ont convenu d'améliorer l'échange d'informations concernant d'éventuels conflits écologiques, d'intégrer davantage les missions actuelles de l'OSCE dans ces efforts et d'accorder en général une plus grande place aux problèmes écologiques dans les activités de l'OSCE. Dans ce cadre, il s'agit en particulier d'étendre les fameuses mesures de confiance et de sécurité aux préoccupations concernant la protection de l'environnement ${ }^{14}$.

\section{$\square$ PNR 42 - Synthèses sur la politique suisse de désarmement}

L'achèvement, à la fin 2000, du Programme national de recherche «Fondements et possibilités de la politique extérieure suisse» (PNR 42) a donné lieu à la publication de plusieurs études sur divers aspects de la politique suisse en matière de contrôle de l'armement et du désarmement ${ }^{15}$.

Au cours des années 1990, la Suisse a reconnu qu'elle retirerait un avantage direct d'une participation active aux systèmes internationaux régissant le contrôle de l'armement et du désarmement. Une étude a examiné la politique de la Suisse dans ce domaine depuis les années 1960 et a été étayée par une analyse approfondie - sur la base de cas particuliers - de cette politique dans le domaine des armes chimiques, biologiques et toxiques, des mines antipersonnel ainsi que des armes légères et de petit calibre. Selon cette étude, la Suisse est passée du statut d'observatrice passive à celui de partenaire active dans les processus internationaux de contrôle de l'armement et du désarmement.

Il faut savoir que la nécessité d'un contrôle de l'armement et du désarmement s'est largement imposée au début des années 1990: dans le domaine de la Convention sur les armes chimiques, la Suisse a par exemple compris, d'une part, que le régime de vérification concernait directement ses activités économiques et, d'autre part, qu'une participation active à la convention servirait les intérêts de sa politique de sécurité tout en lui garantissant une source d'informations plus fiables. En tant que pays industrialisé, la Suisse possède dans le

14. Operational Conclusions of the International Seminar «Strenghtening the OSCE's Role in the Realm of Environment and Security », Berlin, 3-4 juillet 2001.

15. Laurent Goetschel, Politique extérieure en mouvement. Synthèse du PNR 42, Berne: Fonds national suisse de la recherche scientifique, 2000. 
même temps un savoir-faire spécifique qui peut s'avérer fort utile lors de l'élaboration de nouveaux traités et de nouvelles institutions. La Suisse est ainsi parvenue à maintes reprises à dépolitiser des débats houleux en proposant des solutions techniques réalistes. Au stade de l'application d'accords ou de traités, la Suisse a souvent joué le rôle de pionnière. Elle a ainsi contribué à une mise en œuvre aussi rapide et exhaustive que possible des obligations convenues, en incitant les autres Etats à suivre son exemple. Enfin, des experts suisses ont fourni un appui à d'autres Etats dans l'application d'accords sur le contrôle de l'armement ${ }^{16}$.

Dans le domaine du contrôle des exportations, des mécanismes d'évaluation fixés sur le plan international revêtent une importance cruciale. Le cas des exportations de biens dits à double usage est ici l'exemple le plus frappant. En fait, la Suisse doit non seulement s'acquitter des obligations qui découlent de conventions internationales existantes, mais aussi adapter ses procédures et ses règlements à ceux de l'Union européenne pour éviter toute discrimination. Les dispositions européennes figurent notamment dans le Code de conduite sur les exportations d'armements et dans les actions communautaires entreprises pour réglementer les exportations de biens à double usage. Les directives sur la conditionnalité politique adoptées fin 1999 par le Conseil fédéral correspondent d'ailleurs dans une large mesure aux règlements de l'Union européenne ${ }^{17}$.

\subsubsection{VOTATIONS POPULAIRES TOUCHANT À LA POLITIOUE DE SÉCURITÉ ET DE LA PAIX}

\section{$\square$ Révision de la loi sur l'armée et ses conséquences}

En 2001, le DDPS a été très sollicité puisque quatre votations populaires concernaient des objets en lien avec la politique de sécurité. Le 10 juin, le peuple s'est prononcé sur deux modifications de la loi sur l'armée: la première visait à autoriser l'armement de soldats suisses participant à des actions internationales de promotion de la paix (pour leur permettre d'assurer leur propre sécurité); la seconde prévoyait une coopération en matière d'instruction avec des troupes d'autres pays.

ASTM 2001, pp. 260-262.

Pendant la campagne, une scission est apparue tant au sein de la droite (l'UDC et l'ASIN s'opposant au PRD et au PDC) qu'au sein de la gauche (le GSsA n'étant pas du même avis que le PS et que les Verts) ${ }^{18}$. Le peuple a fini par accepter les deux projets de justesse (par 51\% pour l'armement de soldats suisses à l'étranger et par 51,1\% pour la coopération en matière d'instruction; la participation a atteint $42 \%$ ). Les opposants à ces deux projets se regroupaient en particulier dans les cantons de tradition rurale et en Suisse romande. L'étude

16. Stefan Brem, Andrea Heinzer et Thomas Bernauer, Abrüstungs- und Rüstungskontrollpolitik der Schweiz: Schweizer Beiträge zur Stärkung internationaler Abrüstungs- und Rüstungskontrollregime (Synthesis 48), Berne, septembre 2000.

17. Urs Cipolat (in collaboration with Alix Gowlland and Ulrich Karpenstein), Nomproliferation and Switzerland: A Critical Analysis of Switzerland's Legislation concerning Military Export Controls (Synthesis 39), Berne, juin 2000; Walter Kälin et Erika Schläppi, Schweizerische Wirtschaftshilfe und internationale Menschenrechte: Konflikte und Konvergenzen aus völkerrechtlicher Sicht (Synthesis 35), Berne, mai 2000.

18. Au sujet des arguments avancés, voir l'Annuaire Suisse-Tiers Monde 2001, pp. 261-262, et le TagesAnzeiger, 26.5.01. 
Vox réalisée après la votation a par ailleurs montré que ce sont les voix de la gauche - préférant l'argument de l'ouverture aux principes pacifistes - qui ont finalement fait pencher la balance. ${ }^{19}$

Le résultat serré de ce vote a eu des effets sur le programme d'armement 2001, dans la mesure où le conseiller fédéral Schmid a renoncé à l'achat d'avions de transport destinés à acheminer les troupes de promotion de la paix et les équipes de secours en cas de catastrophe. Le DDPS continuera certes de développer le secteur promotion de la paix à long terme, mais il a décidé de renoncer à approfondir ce sujet dans le cadre de l'actuelle Réforme de l'armée XXI (voir ci-dessous sous-chap. 5.2 .5$)^{20}$.

\section{$\square$ Initiatives $d u$ GSsA}

Fin 2001, le peuple était appelé à se prononcer sur deux initiatives lancées par le GSsA concernant la politique de la paix. La première demandait, une nouvelle fois depuis 1989, la suppression de l'armée («Pour une politique de sécurité crédible et une Suisse sans armée»), la seconde exigeait la mise en place d'un service civil volontaire pour la paix ( «La solidarité crée la sécurité: un service civil volontaire pour la paix»). En juin 2001, comme ils l'avaient déjà fait auparavant, le Conseil des Etats et le Conseil national ont très nettement opté pour le rejet de ces initiatives. Le 2 décembre, le peuple et tous les cantons les ont également rejetées. Les résultats des votations, avec respectivement $78 \%$ et $77 \%$ de non, auraient difficilement pu être plus clairs.

[1 ASTM 2000, pp. 230-232.

Il importe de relever ici les conclusions de la Commission d'admission au service civil, qui a tiré un premier bilan de ses activités en janvier 2001. Pour cette commission, l'organisation actuelle du service civil est un "pot-pourri sans caractère». Selon elle, il faut réorienter le service civil pour en faire plutôt un instrument de la politique de sécurité et de la paix de la Confédération, qui autoriserait aussi des interventions collectives à l'étranger ${ }^{21}$.

\section{$\square$ Initiative pour l'adhésion à l'ONU}

【I ASTM 2002, sous-chapitre 5.1 «La Suisse et 1'ONU».

\subsubsection{LA POLITIQUE DE SÉCURITÉ ET DE LA PAIX DANS LE PLAN DIRECTEUR DE L'ARMÉE XXI}

En mai 2001, le Conseil fédéral a soumis le Plan directeur de l'armée XXI à la procédure de consultation ${ }^{22}$. De son propre aveu, le Plan directeur se fonde sur les réflexions du rapport sur la politique de sécurité 2000 La sécurité par la coopération, qui recommande de mettre davantage l'accent sur la participation à la promotion internationale de la paix et sur la gestion des conflits. Aussi, bien que le Plan directeur de l'armée continue d'accorder la priorité à la défense classique du pays, il s'attache à préciser le rôle que jouera la coopération inter-

21. Neue Zürcher Zeitung, 27.1.01.

22. Plan directeur de l'armée XXI. Conception de l'armée suisse à l'aube du XXI siècle. Projet du 2 mai 2001, <www.vbs.admin.ch/internet/f/armee/PUB/alb/ALB_f_010502.pdf>. 
nationale au sein de la future armée. Le texte énumère ainsi les différents moyens dont dispose l'armée pour contribuer à la promotion de la paix et à la gestion des conflits:

- maintien et renforcement de la sécurité, de la stabilité et de la paix, par l'envoi d'unités ou de spécialistes pour prendre part à des interventions (à condition que les opérations soient menées sur un mandat de l'ONU ou de l'OSCE);

- vérification dans le domaine du contrôle des armements et du désarmement;

- contribution à une application plus rigoureuse du droit de la guerre ;

- promotion du contrôle démocratique des forces armées;

- participation aux opérations humanitaires de déminage;

- soutien de l'aide humanitaire, à condition que des moyens civils soient engagés.

Le premier point anticipe déjà sur l'adoption par le peuple de la révision de la loi sur l'armée (voir ci-dessus sous-chap. 5.2.4). Le résultat serré du vote a toutefois obligé les responsables à repousser la mise en œuvre de ces mesures dans le temps, puisque la Suisse n'achètera pas immédiatement les avions de transport nécessaires pour participer à des interventions de grande envergure à l'étranger.

Bien que les milieux politiques aient réservé un accueil mitigé au Plan directeur de l'armée XXI, seuls quelques rares partis et organisations ont émis des critiques, en procédure de consultation, sur les nouvelles compétences qui permettent à l'armée de participer à la promotion de la paix et à la gestion des conflits sur le plan international ${ }^{23}$.

\subsection{BLANCHIMENT - FUITES DE CAPITAUX - CORRUPTION}

Au niveau de l'OCDE, le Groupe d'action financière sur le blanchiment continue à chercher à adapter les moyens de lutte aux nouvelles formes de blanchiment et à inciter les pays jugés non coopératifs à adapter leurs législations. En Suisse, la nouvelle loi sur le blanchiment entrée en vigueur en avril 1998 a permis d'étendre la loi suisse à tous les intermédiaires financiers. Les problèmes dans l'application de la loi sont devenus de plus en plus évidents depuis l'été 2000: système d'autorégulation de la surveillance dans les secteurs concernés difficile à mettre en ouvre, manque d'effectifs au niveau de l'Administration fédérale pour assurer la surveillance, portée de la loi laissant certains secteurs à l'abri du contrôle (transactions immobilières ou commerce d'objets de luxe par exemple) ou contrôle trop pointilleux dans des domaines marginaux (change dans les hôtels ou stations-service). La Suisse a subi des pressions internationales visant à affaiblir le secret bancaire dans le cadre de la lutte contre les fuites fiscales. Elle accorde actuellement l'entraide judiciaire internationale uniquement dans le cas de fraude fiscale (falsification de documents pour échapper au fisc), mais non lors de simple soustraction fiscale (omettre de déclarer certains revenus au fisc).

23. Armeereform XXI: Vernehmlassungsverfahren zum Armeeleitbild und zur Revision der Militärgesetzgebung. Zusammenfassung der Ergebnisse, <www.vbs.admin.ch/internet/d/armee/PUB/alb/MG-VNBer-010815-d.pdf> (n'existe qu'en allemand). 


\subsubsection{LOIS SUISSES ET LUTTE CONTRE LE CRIME ORGANISÉ, LE BLANCHIMENT ET LA CORRUPTION}

\section{$\square$ Rappel des grands axes des changements législatifs des dernières années}

Depuis le début des années 1990, la Suisse a sensiblement renforcé les lois pour mieux lutter contre le crime organisé, le blanchiment et la corruption. L'encadré ci-dessous rappelle les grandes lignes des changements législatifs récents ${ }^{24}$.

\section{Renforcement de la législation contre le crime organisé, le blanchiment et la corruption}

Lois et principales caractéristiques
Date pour l'adoption de nouvelles lois ou leur entrée en vigueur

Série de mesures visant au renforcement de la Entrée en vigueur le 1.8.1994.

lutte contre le crime organisé, avec notamment I'art. 260ter, qui punit la participation ou le soutien à des organisations criminelles.

Loi révisée de 1996 sur l'entraide internationale Entrée en vigueur le 1.2.1997. en matière pénale.

Nouvelle Loi concernant la lutte contre le blanchiment d'argent dans le secteur financier. Le nouvel art. 305ter al. 2 du Code pénal introduit I'obligation pour les intermédiaires financiers d'annoncer aux autorités compétentes leurs soupçons sur des transactions leur paraissant douteuses.
Entrée en vigueur le 1.4.1998. Les intermédiaires financiers ont jusqu'à fin mars 2000 pour soit s'affilier à un organisme d'autorégulation, soit dépendre directement du contrôle de l'Autorité en matière de lutte contre le blanchiment.

Modification du Code pénal réprimant en Suisse Entrée en vigueur le 1.5.2000. la corruption active et passive d'un fonctionnaire. Le nouvel article 322septies punit la corruption active d'agents publics étrangers.

La Suisse adhère à la Convention de l'OCDE sur la Ratification par la Suisse le 31.5.2000. lutte contre la corruption d'agents publics étrangers dans les transactions commerciales internationales.

\section{Rapport de l'Assemblée française concernant les lacunes en Suisse dans la lutte contre le blanchiment}

L'Assemblée nationale française a publié en février 2001 son rapport concernant la Suisse sur les obstacles à la répression de la délinquance financière et du blanchiment $^{25}$. Sur la base d'auditions de juristes et de banquiers ${ }^{26}$, ainsi que de

24. Un encadré plus complet des changements intervenus depuis 1977 se trouve aux pages 241 et 242 de l'Annuaire Suisse-Tiers Monde 2000.

25. Assemblée nationale, Rapport d'information par la mission d'information commune sur les obstacles au contrôle et à la répression de la délinquance financière et du blanchiment des capitaux en Europe, vol. 3, La Suisse, rapporteur: Arnaud Montebourg, 21.2.01, disponible sur Internet $<$ www.assemblee-nationale.fr/2/rap-info/i2311-3.htm>.

26. Ont notamment été auditionnés le procureur général du canton de Genève, Bernard Bertossa, Paul Perraudin, juge d'instruction de Genève, et Paolo Bernasconi. 
rapports de l'OCDE (voir ci-dessous), le rapport Montebourg (du nom du rapporteur de la mission) dénonce le laxisme de la Suisse dans la lutte contre le blanchiment. La Suisse ne réagirait que sous la pression internationale, la loi sur le blanchiment a des limites et les intermédiaires financiers non bancaires sont absents de la lutte antiblanchiment. Les moyens donnés à l'Etat pour lutter contre le blanchiment sont nettement insuffisants. Ce rapport a suscité des réactions très vives de protestation des milieux bancaires et de la Confédération, qui jugent ses critiques trop fortes.

\subsubsection{LUTTE CONTRE LE BLANCHIMENT}

\section{$\square$ Travaux du Groupe d'action financière sur le blanchiment de capitaux}

Le Groupe d'action financière sur le blanchiment de capitaux (GAFI) a été créé par le G7 en 1989; il est intégré à l'OCDE. En 1990, le GAFI avait formulé 40 recommandations d'action pour mieux lutter contre le blanchiment de capitaux ${ }^{27}$. Ce sont des recommandations non contraignantes, mais le GAFI a mis sur pied des mécanismes de pression pour que les pays membres et non membres renforcent progressivement leurs législations afin de se conformer à ces recommandations (publication d'un rapport annuel, exercices annuels d'autoévaluation et évaluations mutuelles périodiques des mesures prises dans différents pays, séminaires dans des pays non membres). Vingt-neuf pays sont membres du GAFI, dont la Suisse, l'Argentine, le Brésil, la Chine, le Mexique, Singapour et la Turquie. Le GAFI soutient aussi la création d'organismes régionaux qui ont des objectifs et missions analogues ${ }^{28}$.

Le rapport annuel ${ }^{29}$ fait le point sur les progrès intervenus et les lacunes. Il met aussi en lumière les tendances dans les méthodes utilisées pour blanchir les capitaux et propose des mesures pour les combattre et pour adapter les mesures de lutte à ces nouveaux défis.

\section{Pays non coopératifs}

Depuis 1998, le GAFI étudie les problèmes posés par les pays et territoires qui ne coopèrent pas dans le domaine de la lutte contre le blanchiment de capitaux $^{30}$. Il a publié en l'an 2000 une première liste de pays et territoires non coopératifs ${ }^{31}$. Ces pays ou territoires sont priées d'adopter aussi rapidement que possible des mesures pour pallier leurs lacunes législatives. Les institutions financières doivent prêter une attention particulière lors de relations d'affaires avec des personnes ou sociétés de ces pays non coopératifs.

Dans son rapport de juin 2001, le GAFI retire quatre pays, jugeant qu'ils ont entrepris des réformes juridiques remédiant aux lacunes constatées une année

27. Les 40 recommandations du GAFI sont disponibles sur Internet <www.oecd.org/fatf/>.

28. Autres organismes régionaux travaillant dans le même esprit que le GAFI: Groupe d'action financière des Caraïbes, Groupe anti-blanchiment de l'Asie-Pacifique, Conseil de l'Europe, Groupe antiblanchiment de l'Afrique orientale et australe et Groupe d'action financière de l'Amérique du Sud (GAFISUD), créé en décembre 2000.

29. GAFI, Rapport annuel 2000-2001, Paris, 22.6.01, 22 p. + annexes. Disponible sur le site Internet du GAFI <www.oecd.org/fatf/>.

30. GAFI, Rapport du GAFI visant à identifier les pays ou territoires non coopératifs. Améliorer l'efficacité, au plan mondial, des mesures de lutte contre le blanchiment, Paris, 22.6.01. Le rapport contient notamment les critères définissant les pays ou territoires non coopératifs.

31. Voir la liste des pays à la page 266 de l'Annuaire Suisse-Tiers Monde 2001. 
auparavant (Bahamas, îles Caïmans, Liechtenstein et Panama); six nouveaux pays ont par contre été ajoutés à la liste en juin 2001 (Egypte, Guatemala, Hongrie, Indonésie, Myanmar et Nigeria) et deux autres en septembre 2001 (Grenade et Ukraine). Les Philippines et Nauru ont même été menacées de «contremesures » accrues: annonce aux autorités des transactions faites avec ces pays, prise en compte du statut suspect lors de l'établissement d'une banque de ces pays dans un pays du GAFI, avertissement au secteur non financier ${ }^{32}$.

\section{Bilan des évaluations mutuelles}

L'OCDE a procédé à un Examen des systèmes anti-blanchiment du GAFI et des procédures d'évaluation mutuelle 1992-199933. Le processus d'évaluation mutuelle est un pilier essentiel des travaux du GAFI, pour voir dans quelle mesure les 40 recommandations sont traduites dans les législations nationales des pays membres et inciter les pays membres et non membres qui présentent des lacunes dans leurs lois à améliorer leur dispositif de lutte. Le niveau du respect des 40 recommandations du GAFI s'est régulièrement amélioré. La législation de dix pays membres du GAFI est conforme aux 28 recommandations qui imposent des mesures obligatoires. La Suisse respecte toutes les recommandations sauf une ${ }^{34}$. Les cinq pays suivants ont des législations nationales non conformes (ou partiellement conformes) à une série de recommandations (de 6 à 16) : Argentine, Canada, Etats-Unis, Japon et Mexique.

Si les lois se sont effectivement améliorées dans les différents pays, des lacunes subsistent dans les procédures d'enquêtes et poursuites de délits. Dans la plupart des pays, les déclarations des opérations suspectes proviennent surtout du secteur bancaire, et très peu des autres intermédiaires financiers. Les saisies et confiscations de fonds, les enquêtes, poursuites et condamnations se font dans quelques pays seulement. L'établissement de la preuve du lien entre des sommes saisies et une activité criminelle est difficile à faire. Le travail des services de renseignements et de surveillance financière est compliqué et exige une approche multidisciplinaire: compétences judiciaires policières, mais aussi nécessité de recourir à des comptables et analystes financiers, système informatique d'information rapide pour les renseignements.

\section{Tendances récentes dans les méthodes de blanchiment}

Dans son Rapport sur les typologies du blanchiment de capitaux publié en $2001^{35}$, le GAFI fait l'inventaire des méthodes et des tendances récentes du blanchiment, examine les menaces qui se profilent et les contre-mesures qui pourraient être envisagées. Le rapport 2001 examine par exemple le cas des services bancaires par Internet. La facilité d'accès via Internet, la dématérialisation du contact entre clients et banques et la rapidité des transactions font que ce moyen peut attirer ceux qui souhaitent blanchir de l'argent. L'autre aspect examiné est le problème du recours à des professionnels du droit, des comptables et conseillers financiers pour aider les criminels à déplacer et dissimuler des pro-

32. Le Temps, 8.9.01.

33. GAFI, Examen des systèmes anti-blanchiment du GAFI et des procédures d'évaluation mutuelle 1992-1999, Paris, 16.2.01, 65 p. Disponible sur le site Internet du GAFI.

34. Elle n'a pas formellement ratifié la Convention des Nations Unies de 1988 contre le trafic illicite de stupéfiants et de substances psychotropes.

35. GAFI, Rapport sur les typologies du blanchiment de capitaux 2000-2001, Paris, 1.2.01, 31 p. Disponible sur le site Internet du GAFI. 
duits illégaux. Certains avocats et comptables peuvent ainsi offrir leurs conseils et services (aider à créer des sociétés, conseils pour des montages financiers et juridiques, introduction auprès de banques, administration de sociétés) et devenir de la sorte (sciemment ou à leur insu) des «ouvreurs de portes» utiles pour les criminels. Le rôle des fiducies a aussi été examiné par le GAFI. Les fiducies (fondation ou société de commandite par exemple) permettent «de protéger des biens ou des actifs de façon à pouvoir les utiliser au bénéfice de certaines personnes ou de certaines fins» (administrer des héritages, gestion financière de sociétés, créer des fonds communs de placement, parrainer des manifestations ou des œuvres caritatives). La fiducie est une construction juridique pouvant être utilisée pour dissimuler une activité illégale, brouiller les pistes du blanchiment, grâce à l'anonymat qu'une fiducie peut offrir au propriétaire ou bénéficiaire réel.

Le GAFI a décidé d'entreprendre une révision des recommandations pour tenir compte de l'évolution des techniques de blanchiment et des points faibles du dispositif de lutte. Les questions suivantes seront notamment traitées: identification des clients et déclaration des opérations suspectes, utilisation abusive de structures sociétaires comme les sociétés, les fondations et fiducies à des fins de blanchiment, «ouvreurs de portes» pour aider à blanchir des fonds d'origine criminelle.

\section{$\square$ Problèmes dans l'application de la loi contre le blanchiment en Suisse}

La nouvelle loi sur le blanchiment entrée en vigueur en avril 1998 a permis d'étendre la loi suisse non seulement au secteur bancaire mais à tous les intermédiaires financiers. La surveillance du système est de la compétence de l'Administration fédérale des finances, alors que les transactions suspectes sont examinées à l'Office fédéral de la police.

La Suisse a mis sur pied un système d'autocontrôle des intermédiaires financiers. Ces derniers avaient jusqu'au printemps 2001 pour soit s'affilier à un organisme d'autorégulation (OAR) reconnu par la Confédération, soit dépendre directement du contrôle de l'Autorité de contrôle en matière de blanchiment (Administration fédérale des finances, Département des finances), autorité qui délivre aussi les autorisations pour les OAR et surveille les activités de ces organes.

La loi introduit l'obligation d'annoncer les transactions douteuses au Bureau de communication en matière de blanchiment (MROS), rattaché à l'Office fédéral de la police (DFJP). Les intermédiaires financiers doivent vérifier l'identité des personnes avec lesquelles ils ont des relations d'affaires et sont obligés d'annoncer les transactions suspectes au MROS. Ce bureau a cinq jours pour vérifier si les soupçons sont justifiés (temps pendant lequel les comptes suspects sont bloqués). Si oui, le dossier est transmis aux autorités de poursuites pénales des cantons concernés.

Dans son rapport annuel ${ }^{36}$, le Bureau de communication en matière de blanchiment relève qu'il a reçu 311 annonces portant sur des soupçons de blanchiment en l'an 2000, dont $77 \%$ ont été transmises aux autorités de poursuite pénale, ce qui montre que la qualité des annonces est bonne. La plupart des communications 
proviennent du secteur bancaire et la part des annonces en provenance de gérants de fortune et de fiduciaires est en augmentation, mais d'autres secteurs sont montrés du doigt pour le peu d'empressement à signaler des opérations suspectes. Seuls $0,6 \%$ des annonces proviennent des assureurs, $0,3 \%$ des agents de change et $2,3 \%$ des avocats; $92 \%$ des communications ont été transmises par les cantons de Zurich (40\% des annonces), de Genève, de Berne, du Tessin et de Bâle-Ville. La part de Zoug est très faible et certains cantons, dont Appenzell et Glaris, où résident un nombre non négligeable d'intermédiaires financiers, n'ont transmis aucune communication.

De nombreux problèmes ont montré les difficultés pour appliquer la nouvelle Loi sur le blanchiment (LBA) en Suisse:

- Système d'autorégulation et de surveillance par l'Administration fédérale des finances $(A F F)$ compliqué à mettre en ouvre. Si le système reposant sur l'autocontrôle fonctionne assez bien dans le domaine bancaire, car la Commission fédérale des banques existait déjà depuis longtemps et a pu être reconnue facilement par l'AFF comme organisme d'autorégulation, la situation s'avérait plus complexe pour les nombreux autres secteurs concernés (assurances, poste, bureaux de change, avocats et notaires, mais aussi stations-service et hôtels), soit 8500 intermédiaires en plus des banques. Il est ainsi admis que le secteur bancaire possède maintenant un contrôle efficace, mais que beaucoup reste à faire dans le cas de certains intermédiaires (conseillers en placement, notaires, gérants de fortune, avocats d'affaires) qui peuvent offrir une couverture pour introduire de l'argent sale dans le circuit financier. Sur les 12 organismes d'autorégulation actuels, certains seraient trop peu motivés par la lutte contre le blanchiment. Des voix se sont élevées dès le printemps 2001 pour dire que la loi était tout simplement impossible à mettre en œuvre. Des spécialistes tels que le professeur Mark Pieth se posent la question de savoir si le système d'autocontrôle est suffisant ${ }^{37}$.

- Déclarations des opérations suspectes. Elles proviennent surtout du secteur bancaire et très peu des autres intermédiaires financiers.

- Manque d'effectifs et démissions en chaîne au sein d'offices fédéraux. Les effectifs des bureaux du MROS et de l'autorité de surveillance à l'Administration fédérale des finances paraissent bien dérisoires face à l'ampleur du contrôle. Le chef de l'Autorité de contrôle, Niklaus Huber, a démissionné en juin 2001, suite à des pressions extérieures (intermédiaires financiers) et des divergences de vues avec ses supérieurs du Département des finances. En août 2001, le conseiller fédéral Kaspar Villiger a décidé d'augmenter l'effectif de l'Autorité de contrôle (AFF) en le faisant passer progressivement de 12 personnes (effectif qui n'avait jamais été complet en raison du rythme des démissions et de la difficulté de recruter du personnel suffisamment qualifié) à 25 postes (pour comparaison, le Secrétariat de la Commission fédérale des banques comprend une centaine de collaborateurs). Ce manque d'effectifs a nettement retardé l'application de la loi: en mai 2001, aucune demande de subordination directe à la surveillance de l'Autorité de contrôle n'avait encore été totalement traitée. Rappelons que le chef du Bureau de communication en matière de blanchiment, Daniel Thelesklaf, avait aussi démissionné 
en l'an 2000, suite à des désaccords avec la direction de l'Office sur le rôle du Bureau, et les effectifs ont dû être augmentés.

- Nécessité de clarifier certains aspects quant à la portée de la loi. En voulant contrôler le maximum de transactions d'argent, la loi risque de se perdre et de devenir difficilement opérationnelle (cas des hôtels et du change dans les stations-service par exemple), laissant dans l'ombre d'autres transactions plus utilisées par des réseaux criminels telles que les transactions immobilières, le commerce d'objets de luxe, la participation boursière et l'augmentation de capital d'entreprises ${ }^{38}$. «Des sommes énormes en provenance du tiers-monde sont ainsi investies dans des sociétés en Europe et aux EtatsUnis, sans que personne sache qui se cache derrière les hommes de paille ou les écrans. Pour des raisons commerciales et de concurrence, la plupart des pays d'Europe ont exclu l'identification dans le cadre de la lutte contre le blanchiment. $»^{39}$ D'autres secteurs, soumis à la loi, sont difficiles à contrôler, notamment en raison de la rapidité des transactions d'achat (négociants de matières premières par exemple).

- Persistance de nouveaux cas de blanchiment spectaculaires. Plusieurs cas de blanchiment ou d'argent de la corruption ont défrayé la chronique ces dernières années: cas des fonds de l'ancien dictateur du Nigeria Abacha ${ }^{40}$, fonds Montesinos, argent de la corruption en provenance de Russie et affaire Borodine, clan Milosevic, argent en provenance d'Ukraine. Des recherches sont aussi menées suite aux attentats aux Etats-Unis de septembre 2001 pour vérifier si des réseaux terroristes islamiques utilisent la place financière suisse pour financer des activités terroristes.

La Commission de gestion des Chambres fédérales a soulevé des questions sur les problèmes de la mise en œuvre de la Loi sur le blanchiment dans son rapport du 22 mai 200141. La Commission de gestion du Conseil national parle de dysfonctionnements accompagnant l'exécution de la loi à l'intérieur du Département des finances et invite le Conseil fédéral à augmenter de manière substantielle les effectifs de l'Autorité de contrôle. Le rapport relève les problèmes d'application de la loi dans le secteur parabancaire et le manque de coopération de la part de certains organismes d'autorégulation.

\subsubsection{PLACE FINANCIÈRE SUISSE, FUITES FISCALES ET SECRET BANCAIRE}

Pendant l'année passée sous revue, la Suisse a subi de différentes manières des pressions d'autres pays, de l'Union européenne et d'organisations internationales (OCDE) sur les questions liées à la place financière suisse et au secret bancaire.

\section{$\square$ Estimations de l'importance des fonds gérés par les banques suisses}

Les informations publiées surtout par la Banque nationale suisse (BNS) montrent l'importance très grande des fonds gérés par la place financière suisse. La

38. Domaine public, $\mathrm{n}^{\circ} 1478,22.6 .01$.

39. Niklaus Huber, cité dans le rapport Montebourg de l'Assemblée nationale française.

40. Voir le Rapport de la Commission fédérale des banques «fonds Abacha», disponible sur Internet $<w w w . e b k . a d m i n . c h>$, et l'Annuaire Suisse-Tiers Monde 2001, pp. 272-273.

41. «Rapport annuel 2000/2001 des Commissions de gestion et de la Délégation des Commissions de gestion des Chambres fédérales » du 9 octobre 2001, Feuille fédérale, pp. 5332 et suiv. 
statistique annuelle de la BNS des opérations fiduciaires comprend les transactions des banques suisses réalisées pour le compte et aux risques de clients étrangers révèle que fin 2000 , le montant des avoirs gérés par les banques suisses pour ces clients s'élevait à 317 milliards de francs, dont plus de 180 milliards en provenance de pays en développement. Ces apports ont augmenté très fortement ces six dernières années: 227 milliards de francs fin 1997 contre 179 milliards fin 1994. Beaucoup de fonds proviennent de paradis fiscaux (37,7 milliards de placements en Suisse en provenance des Antilles britanniques, 19,8 milliards du Panama, 9 milliards des îles Caïmans, 8,1 milliards des Bahamas) ou de pays exportateurs de pétrole, mais aussi de pays plus surprenants: 5,1 milliards de francs gérés dans les banques suisses proviennent de clients du Liberia, 1130 millions de francs de l'Indonésie, 788 millions du Kenya, 713 millions du Nigeria, 642 millions des Philippines, 495 millions du Kazakhstan ${ }^{42}$.

A ce chiffre de 317 milliards s'ajoutent les opérations que les banques effectuent pour leur propre compte (1085 milliards de francs) et les aspects non retenus dans la statistique de la BNS (fortune gérée par les assurances par exemple). La fortune totale gérée par les banques suisses atteint des montants de plusieurs milliers de milliards de francs. Pascal Couchepin avançait en février 2001 le chiffre de 5000 milliards de francs gérés par les banques suisses fin $1999^{43}$. La Suisse est la place financière la plus importante au monde dans la gestion de fortunes de particuliers non gérées dans le pays d'origine du propriétaire, avec une part estimée du marché mondial de 30 à $40 \%{ }^{44}$.

La gestion de fortune a connu une croissance spectaculaire dès le début des années 1990, en raison notamment de quatre facteurs: augmentation de la part des richesses produite par les détenteurs de capitaux (par rapport au revenu du travail), hausse des cours des actions, augmentation très rapide des nouveaux riches, forte croissance des fonds des institutions de prévoyance vieillesse ${ }^{45}$.

\section{$\square$ Enjeux Nord-Sud du débat sur le secret bancaire et les fuites fiscales}

Le débat actuel de l'Union européenne et de l'OCDE sur la concurrence físcale dommageable reste un débat essentiellement entre pays du Nord. Il s'agit par exemple de la France qui pourrait demander à la Suisse de ne pas accueillir simplement de l'argent qu'un contribuable français aurait placé en Suisse pour échapper au fisc de son pays. Les enjeux Nord-Sud existent pourtant. La dérégulation des marchés financiers, les moyens de communication modernes et la mondialisation des marchés ont favorisé les mouvements de capitaux rapides, et peut-être aussi les fuites de capitaux et les montages financiers complexes qui permettent de perdre la trace d'argent sale. En même temps, les pays du Nord demandent qu'au-delà des apports d'aide au développement, les pays du Sud mobilisent mieux l'épargne locale et que les Etats mettent sur pied des systèmes d'imposition efficaces - une large partie de la population et des entreprises

42. Voir aussi, dans la partie «Statistiques» de cet Annuaire, les tableaux statistiques sur les avoirs et engagements à l'étranger des banques établies en Suisse.

43. Neue Zürcher Zeitung, 9.5.01.

44. Source: Sébastien Guex, «Développement de la place financière helvétique et secret bancaire au $20^{\mathrm{e}}$ siècle: la Suisse comme paradis fiscal », Solidarités n $125,15.4 .2001$, p. 4.

45. Ibid. 
dans beaucoup de pays en développement ne paient pas d'impôts directs. Il y a effectivement incohérence entre cette demande d'établir des systèmes de taxation efficaces et le fait que les places financières du Nord accueillent des capitaux issus de la fuite fiscale.

L'organisation Oxfam a procédé à une estimation des pertes fiscales pour les pays en développement liées aux fuites de capitaux pour échapper au fisc de ces pays. Les gouvernements de pays en développement auraient ainsi un manque à gagner, en termes de recettes fiscales qui leur échappent, de 50 milliards de dollars par année, soit presque autant que la totalité de l'aide publique au développement des pays de $1^{\prime} \mathrm{OCDE}{ }^{46}$.

\section{$\square$ Lutte contre la concurrence fiscale dommageable}

Le 27 novembre 2000, 1'Union européenne a adopté les éléments clés d'une directive destinée à permettre l'échange d'informations entre administrations fiscales pour taxer les revenus des placements des résidents d'un pays dans un autre pays de l'Union européenne. Les pays qui le souhaitent peuvent percevoir pendant une période transitoire une retenue à la source au lieu des échanges d'informations. La Suisse est concernée par cette directive puisqu'elle prévoit que l'Union européenne ouvre des négociations avec certains pays tiers pour que ces pays prennent des mesures équivalentes, afin d'éviter des fuites fiscales de l'Union européenne vers ces pays tiers.

Le Comité des affaires fiscales de l'OCDE étudie aussi la question de l'évasion fiscale et de l'échange de renseignements entre administrations fiscales de différents pays. Le renforcement de la lutte contre la concurrence fiscale dommageable est loin de faire l'unanimité au sein de l'OCDE - or, les décisions doivent se prendre à l'unanimité. Les Etats-Unis ont freiné le processus au printemps 2001, ne voulant pas que l'on qualifie de paradis fiscaux les territoires américains qui permettent à des entreprises américaines d'échapper au fisc (entreprises d'exportation installées dans ces territoires par le biais de sociétés «boîtes à lettres»). L'Espagne a opposé son veto à un texte de compromis début septembre 2001 en raison d'un différend avec la Grande-Bretagne, car l'Espagne demande à ce pays de faire cesser les pratiques fiscales dommageables à Gibraltar, alors que la Grande-Bretagne invoque l'autonomie fiscale de ce territoire.

\section{$\square$ Position de la Suisse}

La législation suisse actuelle ne permet pas de lever le secret bancaire et d'assurer l'entraide judiciaire internationale en cas de simple soustraction fiscale (omettre de déclarer certains revenus au fisc), mais l'entraide est effective uniquement en cas de fraude fiscale (falsification de documents pour cacher des

46. Oxfam arrive au chiffre de 50 milliards de dollars par l'estimation suivante: si l'on prend le chiffre, établi par la CNUCED, de 1219 milliards de dollars d'investissements dans les pays en développement en 1998 et que l'on estime le rendement à $20 \%$ et les taux d'impôt à $35 \%$, les pays en question devraient avoir des recettes fiscales de 85 milliards de dollars par an et non de 50 milliards comme cela a été le cas ; 35 milliards de dollars n'ont donc pas été encaissés. D'autre part, le rendement fiscal de la fuite de capitaux, estimée à 700 milliards, représenterait 15 milliards de dollars. Source: Tax Havens: Releasing the Hidden Billions for Poverty Eradication, Oxfam GB Policy Papers, 6/00, $<$ www.oxfam.org $>$. 
revenus au fisc). Ne pas donner d'entraide judiciaire en cas d'évasion fiscale est un aspect critiqué par plusieurs magistrats en Suisse, dont le procureur genevois Bernard Bertossa. Dans le domaine de la lutte contre le blanchiment, il est selon eux très difficile de distinguer les méthodes utilisées pour le blanchiment d'argent d'origine criminelle et les méthodes utilisées dans le cadre de la fuite fiscale. Il existe même un risque lié à ladite «excuse fiscale». Il suffit qu'un détenteur d'un compte puisse rendre crédible que des fonds suspects sont liés à la dissimulation au fisc pour faire arrêter une enquête menée pour blanchiment. Le droit suisse prévoit le principe de "double incrimination", à savoir qu'une entraide judiciaire internationale n'est possible que si un acte est punissable dans les deux pays en question.

La Suisse reste sur la défensive dans ce domaine, en réaffirmant que le secret bancaire n'est pas négociable. La Confédération refuse aussi clairement que la Suisse soit traitée de place financière «offshore». Le Conseil fédéral a affirmé à plusieurs reprises que la législation suisse de lutte contre le blanchiment est nettement en avance par rapport aux législations d'autres pays qui ont une place financière importante (Etats-Unis, Grande Bretagne...). Une partie des critiques en provenance de l'étranger serait motivée par la volonté d'affaiblir la place financière suisse par rapport aux places financières concurrentes. Les banques suisses et le conseiller fédéral Villiger se sont souvent exprimés pour indiquer que les banques suisses n'ont aucun intérêt à attirer de l'argent de provenance douteuse, que les lois mises en place ces dernières années sont adaptées sans devoir remettre en question le secret bancaire.

La Communauté de travail des œuvres d'entraide (CT) a organisé en octobre 2001 un séminaire sur la question des fuites fiscales. Selon certains intervenants au colloque, il serait regrettable que la Suisse applique, suite à des pressions internationales, un système d'impôt à la source sur les placements en Suisse de clients étrangers pour l'Union européenne seulement (avec restitution d'une partie de ces impôts aux pays membres de l'UE) sans appliquer la même règle pour des fonds en provenance de pays en développement. Pour la Communauté de travail, il est important que la loi suisse soit adaptée pour punir la fuite fiscale, et pas seulement la fraude fiscale. La Suisse devrait améliorer l'entraide judiciaire et l'entraide entre administrations fiscales dans ce domaine. Les opérations offshore d'entreprises suisses devraient être mieux contrôlées. Les avoirs confisqués devraient être rendus aux pays de provenance. La Suisse devrait punir non seulement la corruption de fonctionnaires étrangers, mais aussi la corruption dans le secteur privé. Elle devrait réexaminer les conventions de double imposition pour mieux combattre les fuites fiscales et adapter le système de surveillance en Suisse, en remettant en question le système d'autorégulation des intermédiaires financiers et en adaptant les lois sur le blanchiment pour tenir compte des nouveaux moyens de blanchir des capitaux (produits dérivés par exemple $)^{47}$.

47. Sources: Arbeitsgemeinschaft der Hilfswerke, «Steuerwettbewerb und Steuerflucht. Der Süden verliert Milliarden», dossier, Globalt. Globalisierung und Nord/Südpolitik, Bern, n 2, Juli/August 2001 ; idem, «Steuerflucht und internationaler Steuerwettbewerb: Mitverantwortlich für die Armut in der Welt!», Tagung der Arbeitsgemeinschaft vom 10. Oktober 2001, Dokument, ${ }^{\circ} 1$, Dezember 2001. 


\section{SOURCES}

Aktion Finanzplatz Schweiz, Finanzplatz Informationen, bulletin d'information, Drahtzugstr. 28, 4057 Basel.

Arbeitsgemeinschaft der Hilfswerke, «Steuerflucht und internationaler Steuerwettbewerb: Mitverantwortlich für die Armut in der Welt!», Tagung der Arbeitsgemeinschaft vom 10. Oktober 2001, Dokument, $\mathrm{n}^{\circ} 1$, Dezember 2001.

Arbeitsgemeinschaft der Hilfswerke, «Steuerwettbewerb und Steuerflucht. Der Süden verliert Milliarden », dossier, Global+. Globalisierung und Nord/Südpolitik, Bern, nº 2, Juli/August 2001.

Département fédéral des finances, communiqués de presse, 13.6.01.

Office fédéral de la police, communiqués de presse, 19.7.01.

Sansonetti Riccardo, «La problématique des places financières offshore et la position de la Suisse », $L a$ Vie économique, 2-2001.

Domaine public, «Le blanchiment passe par toutes les formes de négoce», 22.6.01.

Le Temps, «Les parlementaires français accusent la Suisse d'hypocrisie et de mauvaise volonté», 22.2.01; «La liste noire du GAFI s'élargit mais épargne le Liechtenstein», 23.6.01; «La crise de la loi anti-blanchiment...», 27.6.01.

Neue Zürcher Zeitung, «Parlamentskommission tadelt Villiger», 30.6/1.7.01.

\section{Ouvrages récents}

Broyer Philippe, L'argent sale. Dans les réseaux du blanchiment, coll. Economie et Innovation, Paris: L'Harmattan, $462 \mathrm{p}$.

OCDE, Affairisme : la fin du système. Comment combattre la corruption, Paris: OCDE, 2000, 315 p.

Trepp Gian, Geldwäscherei und Globalisierung: Vom schmutzigen Geld zum sauberen Kapital, Schriftenreihe des Kaufmännischen Verbands, Zürich, 3/01.

\section{SITES INTERNET}

Administration fédérale des finances/Autorité de contrôle en matière de lutte contre le blanchiment d'argent : <www.admin.ch/efv>.

Bureau de communication en matière de blanchiment d'argent (Office fédéral de la police): <www. admin.ch/bap>.

Commission fédérale des banques: $<w w w . a d m i n . c h / e b k\rangle$.

Conseil de l'Europe: $<w w w . c o e . f r>$.

Déclaration de Berne: $\langle w w w . e v b . c h / d b>$.

Département fédéral de justice et police: <www.ejpd.admin.ch>.

Groupe d'action financière sur le blanchiment de capitaux (OCDE): <www.oecd.org/fatf $>$.

International Anti-Money Laundering Network: <www.imolin.org $>$.

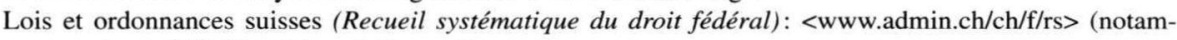
ment sous 955, blanchiment d'argent).

OCDE, site sur la corruption: <www.oecd.org/daf/nocorruption>.

Office for Drug Control and Crime Prevention (ONU): <www.odccp.org $>$.

ONU, Anti-Money Laundering Web-Site : <www.imolin.org $>$.

Transparency International : <www.transparency.org $>$.

Union européenne : <www.europa.eu.int>. 


\subsection{POLITIQUE D’ASILE ET QUESTIONS MIGRATOIRES}

On a célébré en 2001 le 50 anniversaire de la Convention de Genève sur les réfugiés. Le Haut Commissariat des Nations Unies pour les réfugiés a lancé à cette occasion une campagne intitulée "Respect», dont l'objectif est d'attirer l'attention du monde sur le sort des réfugiés. Rejoignant l'initiative du Conseil européen sur les exilés et les réfugiés à l'adresse des gouvernements européens, l'Organisation suisse d'aide aux réfugiés (OSAR) a lancé une pétition pour réaffirmer d'une part la validité des principes à l'origine de la convention face à ceux qui voudraient la considérer comme un instrument obsolète et d'autre part la nécessité de garantir une protection aux exilés.

L'actualité politique de 2001 est marquée par une intense activité législative avec la révision de trois lois: celle sur l'asile, celle sur les étrangers et celle sur la naturalisation. Ce travail d'aggiornamento est appelé à gérer non seulement les formes traditionnelles de migration, mais aussi les nouvelles formes qu'elle prend en correspondance avec les mutations économiques, notamment les migrations des highly skilled ainsi que le travail illégal et, en amont, le trafic d'êtres humains.

\subsubsection{POLITIQUE D'ASILE}

\section{$\square$ Demandes d'asile déposées en 2000}

En 2000, le nombre de personnes frappant à la porte de l'asile en Suisse a diminué de plus de 60\% par rapport au pic (46’068) enregistré en 1999 en raison du conflit au Kosovo, retrouvant le niveau du milieu des années 1990. Cette situation est manifestement imputable à la diminution des demandes provenant de la République fédérale (RF) de Yougoslavie; la région balkanique continue néanmoins de fournir plus d'un demandeur d'asile sur quatre $(20,5 \%$ viennent en effet de la Yougoslavie, $7,4 \%$ de la Bosnie-Herzégovine), suivie par la Turquie $(8,1 \%)$ et l'Irak $(5,2 \%)$.

\section{Graphique 1: Evolution des demandes d'asile 1991-2000}

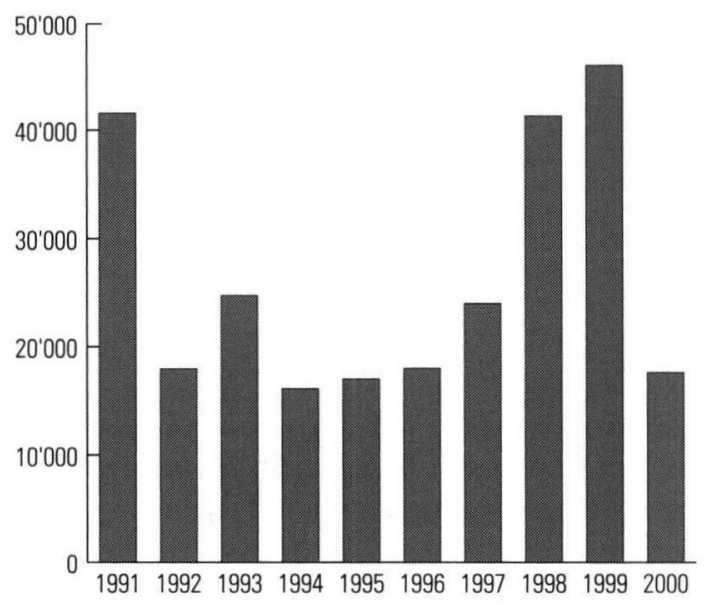

Source: ODR, Statistique en matière d'asile 2000, janvier 2001. 
Tableau 11: Evolution des demandes d'asile 1991-2000 selon le pays d'origine

\begin{tabular}{|c|c|c|c|c|c|c|c|c|c|c|}
\hline Pays d'origine & 1991 & 1992 & 1993 & 1994 & 1995 & 1996 & 1997 & 1998 & 1999 & 2000 \\
\hline Afghanistan & 233 & 278 & 144 & 172 & 114 & 198 & 215 & 245 & 363 & 433 \\
\hline Albanie & 1038 & 546 & 2009 & 50 & 28 & 315 & 3081 & 3752 & 1386 & 339 \\
\hline Algérie & & & 751 & 303 & 388 & 396 & 564 & 529 & 491 & 477 \\
\hline Angola & 796 & 96 & 542 & 1059 & 493 & 468 & 251 & 392 & 545 & 378 \\
\hline Arménie & & & & & & & 163 & 481 & 427 & 368 \\
\hline Bangladesh & 593 & 222 & 122 & 286 & 188 & 170 & 290 & 172 & 155 & 217 \\
\hline Bosnie-Herzégovine & & & 6878 & 3343 & 3534 & 1269 & 1987 & 1891 & 1513 & 1304 \\
\hline Bulgarie & 217 & 27 & 25 & 17 & 33 & & & & & \\
\hline Chili & 7 & 6 & 1 & 4 & & & & & & \\
\hline Colombie & & & & & & & & 452 & 202 & 57 \\
\hline Congo (Rép. dém.) & 1426 & 677 & 362 & 276 & 320 & 695 & 605 & 536 & 523 & 540 \\
\hline Erythrée & & & & & & & & & & 82 \\
\hline Ethiopie & 394 & 94 & 76 & 100 & 142 & 174 & 254 & 243 & 221 & 269 \\
\hline Géorgie & & & & & & & & 813 & 323 & 179 \\
\hline Guinée & & & & & & & 193 & 335 & 388 & 455 \\
\hline Guinée-Bissau & & & & & & & & & 282 & \\
\hline Inde & 886 & 38 & 21 & 48 & 156 & 201 & 203 & 162 & & 135 \\
\hline Irak & 160 & 117 & 79 & 151 & 321 & 413 & 522 & 2041 & 1658 & 908 \\
\hline Iran & 222 & 140 & 95 & 82 & 110 & 134 & 129 & 168 & 206 & 728 \\
\hline Liban & 1352 & 450 & 490 & 170 & 129 & 148 & 184 & & & 94 \\
\hline Libye & & & & & & & & 188 & & \\
\hline Mongolie & & & & & & & & & 164 & 180 \\
\hline Nigeria & 515 & 123 & 72 & 115 & 178 & 253 & 210 & 239 & & \\
\hline Pakistan & 1339 & 631 & 410 & 420 & 437 & 483 & 448 & 314 & 323 & 236 \\
\hline Pologne & 60 & 64 & 16 & 59 & 3 & & & & & \\
\hline RF Yougoslavie & 14205 & 6262 & 5291 & 4124 & 5491 & 6223 & 6913 & 20396 & 28913 & 3613 \\
\hline Roumanie & 2682 & 620 & 113 & 113 & 82 & 70 & & & 271 & \\
\hline Russie & & & & & & & & 174 & 263 & 254 \\
\hline Sierra Leone & & & & & & & 178 & 222 & 756 & 395 \\
\hline Somalie & 910 & 1077 & 2295 & 881 & 478 & 700 & 884 & 610 & 517 & 470 \\
\hline Sri Lanka & 7349 & 2826 & 1744 & 1487 & 1024 & 1965 & 2137 & 1901 & 1487 & 898 \\
\hline Syrie & 179 & 146 & 80 & 44 & 57 & 83 & & & 167 & 156 \\
\hline Tunisie & & & & & & & & 153 & 187 & \\
\hline Turquie & 4324 & 1827 & 1205 & 1068 & 1293 & 1317 & 1395 & 1565 & 1453 & 1431 \\
\hline Ukraine & & & & & & & & 170 & 146 & \\
\hline Vietnam & 86 & 69 & 164 & 215 & 159 & 126 & 122 & 122 & & \\
\hline Autres & 1731 & 1459 & 1681 & 1359 & 1664 & 2187 & 2262 & 2895 & 2738 & 3015 \\
\hline Total & 41584 & 17960 & 24739 & 16134 & 17021 & 18001 & 23982 & 41302 & 46068 & 17611 \\
\hline
\end{tabular}

Source: ODR, Statistique en matière d'asile 2000, janvier 2001.

Note: le tableau compile les données fournies par ce document publié chaque année, qui mentionne explicitement les pays fournissant des flux importants de requérants; ainsi certains pays apparaissent dans la statistique alors qu'ils ne l'étaient pas auparavant (cf. Erythrée pour 2000); de même, I'ODR renonce à publier le détail lorsque le flux en provenance d'un pays semble se tarir (cf. Bulgarie, Chili, Vietnam). Finalement, certains pays apparaissent de manière intermittente, tels I'Ukraine, le Vietnam et la Tunisie ou encore le Liban, la Syrie ou la Libye. Le tableau indique tous les pays mentionnés dans la publication de l'ODR dans le but de rendre compte des changements intervenus dans la provenance des requérants d'asile.

Dans une publication renouvelée quant à la forme et au contenu, l'ODR poursuit son objectif de mieux informer le public sur son activité (ASTM 2000, p. 266). Il met notamment en perspective les données helvétiques par rapport à la situation internationale, telle qu’elle apparait au sein des CIG («Consultations intergouvernementales» regroupant 14 pays européens plus les Etats-Unis, le Canada et l'Australie). Il relève ainsi que la Suisse est le pays ayant connu la plus forte diminution des demandes d'asile cette année: si elle était en tête des 
pays CIG relativement au rapport entre les demandes d'asile et le nombre d'habitants en 1999, elle se trouve en $5^{\mathrm{e}}$ position, après la Slovénie, l'Irlande, la Belgique et les Pays-Bas, en 2000.

\section{$\square$ Octroi de l'asile}

Bien que le nombre de requérants d'asile en Suisse ait fortement diminué, l'ODR a octroyé l'asile à un nombre de personnes à peu près équivalent à celui de 1'an dernier, 2061, ce qui représente un taux moyen de reconnaissance de la qualité de réfugié de $6,4 \%$ sur le total des décisions intervenues; rappelons qu'il était de $14,9 \%$ en 1995 , lorsque le nombre de requérants était semblable. Parmi les décisions d'octroi de l'asile, $67 \%$ ont été prononcées au titre de 1'article 51 de la loi sur l'asile: elles concernent la réunification familiale alors qu'un tiers représente des cas entièrement nouveaux.

En 2000, 16'966 personnes ont bénéficié d'une admission provisoire (25,7\% de moins qu'en 1999): il s'agit surtout de Sri Lankais et de ressortissants de la RF de Yougoslavie, dont les cas ont été traités dans le cadre de l'«Action humanitaire $2000 »$.

미 ASTM 2001, p. 281.

A partir de l'année 2000 et contrairement aux publications précédentes, l'ODR ne fait plus figurer parmi les personnes relevant de l'asile celles dont le statut a été réglé selon la loi sur les étrangers (cas humanitaires et autres réglementations de la Police des étrangers), ce qui représente environ 40'000 personnes. Pour cette raison, l'effectif des personnes relevant du domaine de l'asile est descendu en dessous de la barre des 100'000 personnes.

Parmi les 32'114 personnes habitant en Suisse au titre d'une admission provisoire on compte $45,5 \%$ de femmes et $35,5 \%$ d'enfants en dessous de 14 ans, ces pourcentages s'expliquent par un recours accru au regroupement familial.

Tableau 12: Personnes relevant du domaine de l'asile (état à fin décembre 2000 et 1999)

\begin{tabular}{lccr}
\hline & $\mathbf{3 1 . 1 2 . 2 0 0 0}$ & $\mathbf{3 1 . 1 2 . 1 9 9 9}$ & $\begin{array}{r}\text { Variation } \\
\text { (en \%) }\end{array}$ \\
\hline Effectif total & $\mathbf{9 8 4 8 0}$ & $\mathbf{1 7 1 2 2 3}$ & \\
\hline Réfugiés reconnus & 25534 & 25202 & $1.3 \%$ \\
\hline Cas humanitaires/cas réglés par la Police des étrangers & & 38215 & \\
\hline Admissions provisoires & 32114 & 18907 & $-69.8 \%$ \\
\hline Traitement/exécution en suspens ou bloqué & 13363 & 43494 & $15.9 \%$ \\
\hline Cas en suspens en deuxième instance auprès de la CRA* & 12332 & 10636 & $-56.5 \%$ \\
\hline Cas en suspens en première instance auprès de l'ODR & 15137 & 34769 & \\
\hline
\end{tabular}

Source: ODR, Statistique en matière d'asile 2000, janvier 2001.

* CRA: Commission de recours en matière d'asile.

En 2000, on a enregistré 49'030 départs de Suisse, un chiffre en augmentation par rapport à l'année précédente $(+57,4 \%)$, ce qui prolonge une tendance amorcée depuis quatre ans. Ce résultat est dû entre autres à l'aide au retour au Kosovo, qui a intéressé quelque 16'800 personnes en 2000 contre 15'800 dans la seconde moitié de 1999 . Le succès des programmes d'aide au retour se traduit en une diminution des «départs non officiels» en termes relatifs: ils se montent toujours à environ $13^{\prime} 000$, mais ne représentent plus que $26,8 \%$ contre 
plus de $40 \%$ l'année précédente. On observe une augmentation des rapatriements (4813 contre 2347 en 1999) et une diminution des refoulements vers des pays tiers (533 contre 753).

L'asile a été révoqué pour 656 réfugiés reconnus, aucun danger ne menaçant plus ces personnes. Par ailleurs, l'ODR a levé l'admission provisoire pour 4020 personnes, la plupart des ressortissants sri lankais qui ont bénéficié d'une réglementation cantonale dans le cadre de l'Action humanitaire 2000.

\section{$\square$ Révision partielle de la loi sur l'asile}

L'édition 2000 de l'ASTM (p. 258) observait déjà que la loi sur l'asile entrée en vigueur le $1^{\text {er }}$ octobre 1999, après le référendum du 13 juin, n'avait pas marqué l'aboutissement de la construction de l'édifice législatif; cette matière, toujours brûlante sur le plan politique, est sujette à un développement continu et dynamique, sous la pression manifeste de l'initiative de l'UDC (Union démocratique du centre), dénommée "contre les abus dans le droit d'asile» ${ }^{48}$. L'actuelle révision partielle de la loi - dont l'avant-projet vient de passer en procédure de consultation - revient en effet sur deux points soulevés par l'initiative, notamment l'exclusion de la procédure d'asile des personnes ayant transité par un pays tiers «sûr» et la compression des frais d'assistance.

La réglementation en vigueur autorise le renvoi vers un pays de transit d'un requérant qui y aurait séjourné au moins vingt jours; l'avant-projet ne mentionne plus ce délai. L'OSAR fait valoir qu'une telle norme reviendrait à interdire l'accès à la procédure de toute personne arrivée en Suisse par voie de terre, avec une politique de beggar thy neighbour, au détriment des pays limitrophes ${ }^{49}$. De plus, elle s'écarterait des tendances prévalant dans l'UE, dans la mesure où l'accord de Dublin fait dépendre la compétence d'un pays de la relation entre le requérant et ce pays. Connaissant la faible efficacité de l'actuelle norme sur les Etats tiers, beaucoup d'observateurs se demandent si cette proposition est réaliste ${ }^{50}$.

Le débat autour du financement de l'asile refait systématiquement surface: la réforme vise à réduire les dépenses de la Confédération au titre de l'assistance, qui se montent actuellement à plus de 700 millions de francs. Depuis 1994, la Confédération a abandonné le système de remboursement aux cantons des frais effectifs d'assistance et est progressivement passée à un système forfaitaire. Reprenant quelques éléments du rapport Gerber-Fuhrer (cf. ASTM 2001, p. 284), l'avant-projet propose d'allouer aux cantons une somme globale en fonction des effectifs. Les forfaits devraient tenir compte de la proportion des personnes admises provisoirement qui exercent une activité lucrative, de sorte que les cantons qui leur autorisent plus facilement l'accès au marché du travail seraient récompensés pour cette politique d'ouverture. Les cantons sont en outre encouragés financièrement à prendre des mesures sociales, tels les programmes d'occupation, etc. Une experte en matière de politique d'asile et assistance aux

48. "Asylsuche in der Schweiz - für die SVP ein Missbrauch», Neue Zürcher Zeitung, 14.11.00.

49. "Umstrittene Verteilung von Asyl-"Lasten"», Neue Zürcher Zeitung, 9.10.01.

50. Résumé de la prise de position de l'OSAR sur le Projet de révision partielle de la loi sur l'asile, Berne, 5.9.01. 
demandeurs d'asile ${ }^{51}$ observe que les modifications relatives au financement de l'asile concernent la répartition des charges entre Confédération et cantons et n'intéressent pas directement les requérants; les nouvelles dispositions devront inciter indirectement les cantons à pratiquer une politique d'intégration sociale envers les personnes relevant du domaine de l'asile les plus susceptibles de rester à long terme en Suisse, à savoir les titulaires d'une admission provisoire (permis F). Elle regrette cependant que ce texte ne propose pas un minimum garanti dans les prestations aux demandeurs d'asile à l'intention des cantons, à l'instar de ce qui se fait dans d'autres pays et notamment en RFA.

Toujours au chapitre de la compression des dépenses, l'avant-projet propose que le remboursement des frais d'assistance aux cantons de la part de l'ODR se fasse non pas en fonction de la durée effective du séjour des requérants, mais en fonction d'une durée moyenne. Ce système représente une incitation financière pour que les cantons exécutent sans délai les décisions de l'ODR, en les rendant directement responsables des frais encourus en raison d'une éventuelle attitude plus clémente à l'égard des requérants menacés d'expulsion. D'aucuns observent que la mise en œuvre de cette disposition poussera davantage de requérants déboutés à entrer dans la clandestinité.

La révision porte aussi sur le règlement des cas humanitaires. Actuellement, un requérant peut demander une admission provisoire si, au bout de quatre ans, la procédure le concernant n'a pas abouti à une décision. L'ODR propose de revenir à l'octroi du permis B, comme c'était le cas il y a quelques années encore, mais propose de porter à six ans le délai à partir de l'obtention de l'admission provisoire (et précisément pas du dépôt de l'asile), au bout duquel le requérant pourrait revendiquer un droit au permis de séjour. Cette proposition a été rejetée par l'OSAR, qui craint que l'allongement du délai ne se traduise par une diminution importante des permis délivrés pour raisons humanitaires.

Finalement, l'avant-projet de révision partielle de la loi sur l'asile de l'ODR prévoit que la notification des décisions de non-entrée en matière parvienne directement aux requérants, court-circuitant ainsi les éventuels mandataires et affaiblissant la défense des intérêts des demandeurs d'asile. Il propose l'abolition des comptes de sûreté, ce prélèvement de $10 \%$ sur les salaires des demandeurs d'asile professionnellement actifs effectué au titre d'une contribution aux frais de procédure. Ce système occasionnant trop de frais de gestion, il serait remplacé par une taxe fixe de 100 francs par mois pour les salaires à partir d'un montant de 1300 francs; contrairement aux comptes de sûreté actuellement retournés aux demandeurs d'asile qui quittent la Suisse, ces taxes ne seraient pas remboursables. L'OSAR, qui se félicite de la suppression des comptes de sûreté, dénonce la double imposition frappant des demandeurs d'asile déjà imposés à la source ${ }^{52}$.

51. Denise Efionayi-Mäder, Sozialhilfe für Asylsuchende im europäischen Vergleich, Neuchâtel: Forum suisse pour l'étude des migrations, 1999; Denise Efionayi-Mäder, Milena Chimienti, Janine Dahinden et Etienne Piguet, Asyldestination Europa. Eine Geographie der Asylbewegungen, Zürich: Seismo, 2001.

52. «Asile: une taxe pour financer les frais liés aux requérants? », Le Temps, 5.9.01. 


\section{$\square$ Des retours et des renvois}

L'exécution des décisions de renvoi ou de non-entrée en matière a toujours représenté un point faible de la mise en ouvre de la loi sur l'asile, auquel les autorités ont consacré beaucoup d'attention ces dernières années. Cela s'est traduit par la mise sur pied de programmes d'aide au retour gérés conjointement par l'ODR et la DDC.

Da ASTM 2001, p. 280; ASTM 2000, p. 261; ASTM 1999, p. 168

Pareille approche, mêlant incitations et persuasion, est largement consensuelle; de plus, les chiffres relatifs à l'asile mentionnés au début de cet article (cf. supra point «Demandes d'asile déposées en 2000 ») démontrent l'efficacité de ces dispositifs.

Il est dès lors d'autant plus surprenant que des incidents graves aient marqué les renvois: le $1^{\text {er }}$ mai 2001, le requérant nigérian Samson Chukwu est mort par asphyxie dans une prison valaisanne, alors qu'il résistait à un renvoi forcé ${ }^{53}$. En juillet 2001, un médecin et des policiers ont été condamnés pour homicide par négligence suite au décès d'un Palestinien lors de son expulsion deux ans auparavant $^{54}$. En commentant le verdict, l'OSAR a réitéré la demande d'adoption d'une base légale claire concernant le traitement des personnes refoulées ${ }^{55}$. Le groupe de solidarité alémanique augenauf a attiré efficacement l'attention sur les cas des personnes refoulées contre leur volonté et déportées dans des conditions jugées parfois scandaleuses par les passagers des vols de ligne ${ }^{56}$.

Par ailleurs, et au-delà de ces cas extrêmes, les programmes d'aide au retour se sont poursuivis avec plus ou moins de succès; l'efficacité des programmes a l'intention des demandeurs d'asile kosovars contraste avec le bilan en demiteinte dans d'autres cas, voire avec l'opposition manifestée à leur égard par les ressortissants des pays de la Corne de l'Afrique: Somalis, Ethiopiens et Erythréens $\mathbf{s}^{57}$.

La résistance au retour est à l'origine d'un mouvement de solidarité né au printemps 2000 dans le canton de Vaud, dénommé «En quatre ans on prend racine»; il regroupe des Kosovar-e-s qui, bien que vivant en Suisse depuis plus de cinq ans, n'ont pu bénéficier pour diverses raisons du dispositif Action humanitaire 2000. Le groupe sollicite l'appui des autorités cantonales auprès de Berne, prenant exemple du succès de l'intervention vaudoise en faveur des exsaisonniers yougoslaves. On assiste ici à la première forme de mobilisation collective dans le domaine de l'asile, prélude au mouvement des sans-papiers qui a pris son essor en 2001.

\section{$\square U E$ : l'adhésion à Schengen en discussion}

L'ODR a toujours regretté que la Suisse ne fasse pas partie des accords européens de Schengen et Dublin (ASTM 2000, p. 264), argumentant que cela se

53. «Un requérant meurt en se débattant avec des policiers», Le Temps, 2.5.01.

54. «Un médecin est condamné après la mort d'un requérant», Le Courrier, 4.7.01.

55. Communiqué de presse de l'OSAR, 3.7.01.

56. «Des limites à l'usage de la force?», Vivre ensemble, février 2001.

57. «Teilerfolg der Rückführung in Bosnien. Positiver Trend - Abschied von Illusionen », Neue Zürcher Zeitung, 26.3.01; «Aide au retour: les exilés éthiopiens n'en veulent pas», Planète Exil, mars 2001; «Revolte gegen Flüchtlingsbeamte», Bulletin augenauf, $\mathrm{n}^{\circ} 31$. 
traduisait par un isolement que le pays paie avec une proportion très élevée de demandeurs d'asile. Ainsi, au début 2001 la Suisse prépare le dossier des nouvelles négociations bilatérales avec l'Union européenne: elle souhaite conclure un accord d'association aux accords de Schengen qui organisent la coopération policière et judiciaire entre 13 pays de l'UE. En contrepartie, elle se déclare prête à supprimer le contrôle des personnes à ses frontières. Berne aspire également à signer une convention parallèle à la Convention de Dublin de 1990, qui détermine l'Etat responsable de l'examen des demandes d'asile et permet d'y renvoyer les illégaux. Elle s'inspire des accords d'association à Schengen et Dublin déjà signés par la Norvège, qui a rejoint l'espace Schengen en mars 2001 bien qu'elle ne soit pas membre de l'UE.

La Suisse a entrepris de vérifier son système de sécurité intérieur (USIS) et notamment les contrôles aux frontières; elle étudie les conditions et les modalités de participation à la banque européenne informatisée sur la criminalité (SIS) et à la banque d'empreintes digitales (Eurodac), l'instrument technique de la mise en application de l'accord de Dublin. De son côté, l'UE a accepté début mars 2001 d'entrer en matière sur la négociation pour l'association de la Suisse à ces accords, en dépit de sa non-adhésion à l'UE.

Ce premier résultat sur le front international contraste avec une fragilisation du consensus à l'intérieur du pays quant aux bienfaits d'une éventuelle association ou aux sacrifices que cette association comporte. La Conférence des gouvernements cantonaux, appelée à formuler un mandat de négociation préliminaire pour le Conseil fédéral, fait état d'un «grand scepticisme» quant à l'urgence de nouvelles négociations. Tout en ne s'opposant pas à la poursuite d'entretiens exploratoires, 22 cantons sur 26 estiment ne pas pouvoir évaluer pleinement les avantages et les inconvénients d'une collaboration dans un domaine qui touche à la souveraineté cantonale. De plus, les cantons frontaliers redoutent la suppression des contrôles aux frontières ${ }^{58}$. Par ailleurs, des commentateurs font valoir que les accords de Schengen sont en passe de devenir partie de l'acquis communautaire, aux termes du Traité d'Amsterdam, soumis aux décisions des seuls pays membres de l'Union; en cas d'association, la Suisse ne pourra pas contribuer à l'évolution des normes dans ce domaine pourtant applicables dans le pays, ce qui entraîne une perte importante de souveraineté ${ }^{59}$.

\subsubsection{POLITIQUE DE MIGRATION}

\section{$\square$ Politique d'admission: des permis pour les très qualifiés}

Sous la pression des milieux économiques, le gouvernement fédéral a décidé fỉn mai 2001 d'augmenter pour la première fois depuis 1991 le contingent d'autorisations de séjour à l'année $(+5000=+30 \%)$ et de courte durée $(+6000$ $=+33 \%$ ) pour les personnes très qualifiées alors qu'il est resté sourd aux demandes des agriculteurs et des milieux touristiques ${ }^{60}$. Ce faisant, le Conseil fédéral traduit en pratique les grandes orientations de sa politique d'admission,

58. «Berne relativise le scepticisme des cantons envers l'espace Schengen», Le Temps, 14.4.01.

59. «Ein bisschen beitreten kann man nicht», Die Weltwoche, 29.3.01.

60. «Lockerung der Ausländerpolitik», Neue Zürcher Zeitung, 25.5.01; «Le Conseil fédéral ouvre les vannes à la main-d'œuvre étrangère qualifiée», Le Temps, 25.5.01; «Ruth Metzler: notre politique n'a pas pour vocation de subventionner l'économie», Le Temps, 8.2.01. 
esquissées par la nouvelle loi sur les étrangers, qui vise à privilégier systématiquement les entrées de personnes au profil de formation élevé.

\section{$\square$ Politique d'admission: la révision totale de la loi sur les étrangers}

En juin 2001, le Département fédéral de justice et police a publié les résultats de la procédure de consultation de l'avant-projet de la nouvelle loi sur les étrangers (LEtr), dont on retrouve les grandes lignes dans l'édition 2001 de l'ASTM (p. 288). Rappelons que la loi ne concernera que les étrangers non ressortissants de l'UE et de l'AELE, dans la mesure où pour ceux-ci l'accès au territoire et le traitement sont réglés par les accords bilatéraux sur la libre circulation des personnes conclu entre la Suisse et l'UE.

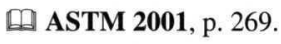

Le nombre très élevé des prises de position ainsi que des propositions de modification témoigne de l'intérêt et des controverses que suscite ce sujet ${ }^{61}$.

La proposition de loi a été rédigée après la période de crise des années 1990 , quand pour la première fois de nombreux travailleurs étrangers ont eu assez de droits sociaux pour solliciter le système suisse de sécurité sociale. Tirant les enseignements de cette expérience, les auteurs de l'avant-projet de loi s'emploient à limiter les risques que cela ne se reproduise. Cette prudence se traduit d'une part par le recrutement privilégié de main-d'œuvre qualifiée et d'autre part par des normes prévoyant la révocation de toutes les autorisations de séjour lorsque l'étranger doit recourir à l'assistance publique.

Les critiques les plus percutantes visent la conception même de la politique d'admission. Un ouvrage collectif rédigé par des personnes et des associations actives dans la lutte contre le racisme et pour la défense des droits des étrangers $^{62}$ reproche à la LEtr d'instituer une discrimination à l'admission en Suisse des personnes en raison de leur origine nationale, en établissant un clivage net entre les ressortissants UE-AELE et les autres. De plus, en barrant la route à toute possibilité de séjour «légal» pour ces derniers lorsqu'ils ne sont pas hautement qualifiés, la LEtr contribue inévitablement à fabriquer des clandestins. On taxe d'irréaliste une politique de recrutement qui mise sur les seuls travailleurs qualifiés: le discours à la mode réclame des «cerveaux» mais la réalité de l'emploi non déclaré se charge de démontrer que les autres sont tout autant nécessaires (cf. infra point «Politique de non-admission: les sans-papiers et le travail au noir»). Ces dispositions vont précariser davantage les travailleurs de la restauration, du bâtiment et de l'agriculture ainsi que les employés domestiques, dénonce la Communauté genevoise d'action syndicale.

De leur côté, les milieux patronaux invitent à la prudence et souhaitent ne pas arrêter une politique rigide avant de connaître l'impact de la libre circulation avec les pays de l'UE. Les autorités cantonales genevoises, quant à elles, dénoncent l'hypocrisie des normes contenues dans la LEtr: «Feindre d'ignorer les flux Nord-Sud comme le font les dispositions proposées aura pour seul effet de surcharger le secteur de l'asile. ${ }^{63}$

61. Office fédéral des étrangers, Compte rendu des résultats de la procédure de consultation relative à l'avant-projet de Loi fédérale sur les étrangers (LEtr), juin 2001.

62. Retournons la Letr (Loi sur les étrangers) à son expéditeur!, Editions CORA/Le Courrier, 2001.

63. «Genève dénonce une loi qui fera de la Suisse une usine à clandestins », Le Temps, 7.11.00. 
Par ailleurs, les milieux proches des immigrés observent que le remplacement du statut de saisonnier par les permis de courte durée est davantage cosmétique qu'innovateur, puisqu'il se borne à rendre possible un regroupement familial sans le reconnaître comme un droit, et, de plus, soumet cette éventualité à la condition de ne pas devoir recourir à l'assistance. Finalement, ces milieux reprochent à l'avant-projet d'avoir repris la vieille orientation de «lutte contre la surpopulation étrangère » de la loi de 1931 en la renommant, à l'aide d'une formulation plus «moderne», comme un «rapport équilibré entre Suisses et étrangers ». D'autres critiques se fondent sur l'insuffisante prise en compte du développement démographique de la Suisse ou encore sur l'encouragement à la «fuite des cerveaux» au détriment des pays du Sud.

Mentionnons encore l'accueil réservé en procédure de consultation à l'initiative parlementaire Goll, visant l'introduction pour les femmes migrantes d'un droit de séjour indépendant de l'état civil dans le but de réduire leur dépendance d'un conjoint violent. Si la majorité des cantons souhaite subordonner la délivrance d'un permis de séjour pour un étranger conjoint d'un ressortissant suisse à la condition de leur vie commune, tous les milieux proches des immigrés ainsi que dix cantons se prononcent en faveur de l'introduction d'un droit de séjour suite à la dissolution de la communauté conjugale ${ }^{64}$.

Dans les commentaires lors de la procédure de consultation, on peut par ailleurs relever une tendance critique qui reproche au projet de conférer trop de nouveaux droits aux étrangers non UE-AELE; elle estime notamment par trop généreuse la réglementation du regroupement familial et souhaite que la loi mentionne explicitement le respect de la capacité d'accueil de la Suisse comme principe à la base de la politique migratoire. Divers milieux, aussi bien patronaux que syndicaux, considèrent comme inacceptable la limitation du recrutement aux seules personnes hautement qualifiées et désirent que du personnel moins qualifié puisse être admis en Suisse, notamment pour des séjours de courte durée. D'autres critiquent le manque de transparence, d'équité et de cohérence de la politique d'admission.

\section{$\square$ Politique de non-admission: les sans-papiers et le travail au noir}

L'actualité politique a été marquée en 2001 par l'essor du mouvement des sanspapiers, qui s'est manifesté par l'occupation de certaines églises. Ce mouvement réunit des personnes entrées légalement mais restées une fois leur autorisation échouée ou qui se sont vu retirer une autorisation préalable - à cause du chômage, du recours à l'assistance, d'un divorce, du décès du conjoint, de la perte d'une autorisation provisoire ou du refus d'une demande d'asile - ainsi que des personnes entrées illégalement dans le pays grâce au recours à des filières de passeurs. Notons qu'elles proviennent avant tout de pays où la politique d'admission interdit un recrutement actif: en d'autres termes, les sanspapiers représentent en quelque sorte le «tiers-monde» parmi nous.

C'est dans le canton de Vaud, à Fribourg, à La-Chaux-de-Fonds ${ }^{65}$, mais aussi, plus timidement, à Genève, Berne, Bâle et Zurich que, depuis l'été 2001, le

64. Office fédéral des étrangers, Résumé des prises de position concernant l'initiative parlementaire Goll (96.461) «Droits spécifiques accordées aux migrantes», Berne, février 2001.

65. A Lausanne, le mouvement concerne exclusivement les demandeurs d'asile déboutés kosovars (cf. supra point «Des retours et des renvois»), alors qu'à Fribourg et Neuchâtel la mobilisation embrasse 
mouvement social des sans-papiers s'emploie à révéler la situation de milliers de personnes, le plus souvent travailleurs et travailleuses, qui n'ont aucune perspective de voir un jour leur statut s'améliorer, afin de solliciter leur régularisation comme solution globale. Pour la première fois, les «travailleurs de l'ombre » sortent à découvert pour mener une revendication collective.

Pourquoi un mouvement maintenant? Relevons la coïncidence entre la mobilisation et la procédure de consultation sur la nouvelle loi sur les étrangers qui, une fois approuvée, bétonnera la distinction entre étrangers en raison de leur origine et interdira toute stabilisation pour une main-d'œuvre qui n'est pas très qualifiée en provenance des pays du Sud ${ }^{66}$. Ce mouvement fait éclater au grand jour les insuffisances de la loi que l'on s'apprête à approuver.

La presse a avancé plusieurs explications pour rendre compte du fait que le mouvement a pris plus d'ampleur en Suisse romande: écho au mouvement analogue en France, attitude bienveillante des autorités cantonales ou encore de la population $^{67}$. L'étude de Piguet et Losa ${ }^{68}$ incite par contre à identifier la cause principale du caractère en partie régional de la mobilisation dans la plus grande ampleur du phénomène du travail non déclaré des immigrés en Suisse francophone.

Ce n'est pas la première fois que l'on soulève la question des clandestins en Suisse mais, jusqu'il y a dix ans, le débat concernait avant tout les membres - interdits de séjour - des familles de travailleurs admis officiellement, dont notamment des enfants qui ne pouvaient être scolarisés régulièrement. Aujourd'hui, les sans-papiers sont des travailleurs sans aucune perspective d'amélioration de leur statut ${ }^{69}$.

Dans le débat autour de cette question se mêlent souvent plusieurs aspects du problème: les travailleurs étrangers ne possédant pas un titre de séjour ne représentent qu'une partie des personnes effectuant un travail non déclaré pour se soustraire à la fiscalité ou au paiement des assurances sociales (travail au noir ou au gris), qui, elles, sont tantôt des étrangers résidents, tantôt des nationaux ${ }^{70}$. Certes, dans l'impossibilité de vivre de l'assistance, la grande majorité des personnes sans statut légal sont des travailleurs. Se pose alors la question de savoir si c'est le travail au noir qui appelle les clandestins ou si ce sont les clandestins qui produisent l'économie souterraine: il apparaît clairement que les opportunités du marché de l'emploi fonctionnent comme un aimant attirant cette maind'œuvre disposée à exercer des travaux nécessitant des qualifications faibles. On redécouvre ainsi une vieille loi de l'économie des migrations qui identifie dans les facteurs d'attraction ( $p u l l$ ), inhérents aux pays d'immigration, les déterminants majeurs - du moins à court terme - des dynamiques migratoires.

tous les cas de figure des sans-papiers, soulignant leur condition de travailleurs. Le mouvement a bénéficié de l'appui de certains élus locaux. La mobilisation n'est cependant pas parvenue à inscrire cette question à l'ordre du jour des Chambres fédérales.

66. Or, une étude récente atteste du manque de main-d'œuvre non qualifiée dans certaines branches économiques, telles que l'agriculture, la restauration et l'hôtellerie; cf. Etienne Piguet et Stefano Losa, Demande de main-d'œuvre du domaine de l'asile en Suisse et ampleur du travail clandestin, Neuchâtel: Forum suisse pour l'étude des migrations, 2001, pp. 1-72.

67. «Les révoltes des sans-papiers tributaires des politiques cantonales », Le Temps, 22.8.01.

68. Etienne Piguet et Stefano Losa, op. cit.

69. Le numéro de septembre 2001 de Carrefour est consacré à cette question.

70. Denise Efionayi-Mäder et Sandro Cattacin, Illegal in der Schweiz. Eine Uebersicht zum Wissenstand, Neuchâtel: Forum suisse pour l'étude des migrations, 2001. 
Les autorités ont opposé une fin de non-recevoir aux revendications du mouvement $^{71}$ : elles refusent toute régularisation, évoquant 1 '«appel d'air» que cela provoquerait. Pareil argument feint de méconnaître que ces sans-papiers exercent déjà un travail: les milliers de sans-papiers correspondent aux milliers de postes de travail qui ne trouvent pas preneur sur un marché contingenté du travail, auquel les personnes non UE/AELE n'ont aucun accès. Tout en s'opposant à une régularisation, la Commission fédérale des étrangers (CFE) a le mérite de reconnaître l'existence d'un vrai problème: elle propose de durcir les sanctions à l'encontre des travailleurs au noir ainsi que de leurs employeurs et de créer des bureaux de médiation dans les cantons pour conseiller les clandestins sur les possibilités de régularisation ${ }^{72}$.

Signalons que la LEtr prend en compte la question des étrangers travaillant sans titre de séjour: elle durcit notamment les peines à l'encontre des employeurs fautifs - jusqu'ici traités avec bien plus de clémence que les employés - en augmentant l'emprisonnement et l'amende et en excluant les entreprises de l'adjudication des mandats publics ${ }^{73}$. Face à la montée du travail non déclaré, instrument de flexibilisation de l'emploi qui ne concerne de loin pas les seuls étrangers, le Département fédéral de l'économie rédige pour fin 2001 le message relatif au projet de loi contre le travail au noir en général: le texte comprend un renforcement des sanctions, des allégements administratifs, des mesures contre le travail pseudo-indépendant ainsi qu'un renforcement des compétences des commissions paritaires et tripartites ${ }^{74}$.

\section{$\square$ Politique d'intégration: refonte de la loi fédérale sur la naturalisation}

La politique d'intégration, qui jouit désormais d'un consensus certain, avance sur les plans tant local que fédéral. En Suisse romande, le débat autour de la pleine participation des étrangers à la vie publique fait des progrès timides mais réels. Si la nouvelle Constitution neuchâteloise accorde aux titulaires d'un permis d'établissement le droit de vote cantonal (sur le plan communal, ce droit leur est reconnu depuis le siècle dernier), la Constituante vaudoise, en suivant l'exemple jurassien, propose de donner le droit de vote et d'éligibilité sur les plans communal et cantonal aux étrangers ${ }^{75}$. Malheureusement, en mars 2001, Genève a refusé en votation populaire les droits politiques communaux aux étrangers résidant depuis huit ans en Suisse à une courte majorité, montrant néanmoins que les mentalités évoluent si l'on tient compte du refus cinglant infligé à des propositions analogues en 1993.

Après les échecs de 1983 et 1994 mais s'appuyant sur les travaux du Conseil de l'Europe en matière de nationalité, le Conseil fédéral avance une proposition de refonte de la loi sur la naturalisation qui est sans conteste la mesure la plus innovatrice en matière d'intégration. Dans un avant-projet envoyé en procédure de

71. «Ruth Metzler fait la sourde oreille», Le Courrier, 12.6.01; «Une amnistie en suit une autre», Le Courrier, 15.9.01.

72. «La CFE a son idée pour diminuer le nombre de sans-papiers », Le Temps, 29.8.01.

73. Article 103 de l'avant-projet de LEtr.

74. Les résultats de la procédure de consultation sont disponibles sur la page Internet <www. auslaender.ch/arbeitsmarkt/index_f.asp >.

75. Cette proposition semble se heurter à une résistance importante auprès de la population: «Que restet-il à sauver de la nouvelle Constitution vaudoise?», Le Temps, 18.10.01. 
consultation en février 2001, le gouvernement propose avec une certaine audace non seulement la naturalisation facilitée des enfants d'immigrés, mais aussi de conférer d'emblée la nationalité suisse à leurs enfants nés sur le sol helvétique (selon le principe du droit du sol). Reprenant la plupart des propositions émanant du groupe d'experts «Nationalité», le gouvernement entend créer un droit de recours en cas de refus, en réponse au cas jugé inacceptable des votations discriminatoires de Emmen en 1999 sur les naturalisations ${ }^{76}$.

ASTM 2000, p. 271.

L'accueil réservé par le monde politique à ces propositions est différencié: si la naturalisation facilitée des jeunes de la deuxième génération - en clair une harmonisation des procédures et des frais qui en découlent - est plébiscitée, les deux autres propositions suscitent scepticisme ou réserve. Au droit du sol pour la troisième génération on préfère que les parents manifestent leur volonté de faire acquérir la nationalité suisse à leurs enfants, et au droit de recours pour les candidats déboutés on oppose le principe de l'autonomie communale ${ }^{77}$. Au terme de la procédure de consultation, le droit de recours apparaît plus consensuel que le droit du sol pour la troisième génération ${ }^{78}$.

\section{SOURCES}

Asyl, Schweizerische Zeitschrift für Asylrecht und Praxis, Schweizerische Flüchtlingshilfe, Berne.

Asylon, revue de l'Office fédéral des réfugiés, parutions en 2000-2001.

Office fédéral des réfugiés, communiqués de presse, parutions en 2000-2001.

Office fédéral des réfugiés, Statistique en matière d'asile 2000, janvier 2001.

Chronologie der Flüchtlingspolitik, Schweizerische Flüchtlingshilfe, parutions en 2000-2001.

Planète Exil, Organisation suisse d'aide aux réfugiés, parutions 2000-2001.

Vivre ensemble, Bulletin de liaison pour la défense du droit d'asile, Genève.

Bulletin augenauf, Berne.

Carrefour, journal des Centres de contact Suisses-immigrés.

\section{SITES INTERNET}

Administration fédérale: <www. admin.ch >.

Administration fédérale, communiqués de presse: $\langle w w w$. admin.ch/cp/f $\rangle$.

Office fédéral des réfugiés : <www. asyl.admin.ch $>;<w w w . ~ o d r . a d m i n . c h>$.

Office fédéral des étrangers: $<w w w . a u s l a e n d e r . c h / B f A>$.

Organisation suisse d'aide aux réfugiés : <www.sfh-osar.ch $>$.

Haut-Commissariat des Nations Unies aux réfugiés: <www.unhcr.ch>.

Le Courrier: <www.lecourrier.ch>.

Site d'information créé par le Comité référendaire contre le démantèlement du droit d'asile: <www.asile. ch>; e-mail: <asile@worldcom.ch>.

Institut de science politique de l'Université de Berne : <www.anneepolitique.ch>.

Human Rights Watch: <www.hrw.org >.

Association romande contre le racisme: <www.AcorSosRacisme.org $>$.

76. «Ohne Willkür zum Schweizer Pass», Neue Zürcher Zeitung, 1.2.01.

77. «Le projet de Ruth Metzler suscite les critiques au sein de la droite», Le Temps, 2.2.01.

78. Pour consulter les résultats de la procédure de consultation, voir <www.auslaender.ch/news_ info/index_f.asp?lang=f $>$. 


\subsection{PROJET DE FONDATION SUISSE SOLIDAIRE}

Le Conseil fédéral a remis son message relatif à l'initiative populaire de l'UDC (initiative sur l'or) le 28 février 2001, avec la recommandation de rejeter cette initiative. Le débat parlementaire dans chacune des deux Chambres fédérales a clairement débouché d'une part sur la recommandation de rejeter l'initiative sur l'or et d'autre part sur le soutien du contre-projet à cette initiative, prévoyant une répartition à parts égales du produit de la vente des réserves excédentaires d'or de la Banque nationale suisse pendant trente ans, entre la Fondation Suisse solidaire (encore à créer), l'AVS et les cantons.

\subsubsection{BREF RAPPEL HISTORIQUE}

Bien que l'idée remonte à 1997, le projet de création d'une Fondation Suisse solidaire (FSS) a été avancé par le Conseil fédéral dans son message du 17 mai $2000^{79}$, en liaison avec la vente des réserves d'or - estimées à 1300 tonnes - dont la Banque nationale suisse (BNS) n'a plus besoin pour mener sa politique monétaire.

미 ASTM 2001, pp. 293-296.

\subsubsection{DÉVELOPPEMENTS POLITIQUES MARQUANTS EN 2001}

Les résultats de la procédure de consultation ont été rendus publics le 24 janvier 2001 et ont montré l'attachement des cantons et de la majorité des partis à la création de la FSS.

La Commission de l'économie et des redevances du Conseil des Etats (CER-E) a proposé, le 2 février 2001, de traiter l'utilisation des 1300 tonnes d'or en une seule fois, pour permettre d'opposer un contre-projet à l'initiative sur l'or de l'Union démocratique du centre (UDC). Cette commission propose en outre que seuls les revenus du capital issu de la vente de l'or soient utilisés (la valeur réelle du capital demeurant intacte), et ce pour une durée de trente ans. La répartition de ces revenus se ferait à parts égales entre la FSS, les cantons et l'AVS. $\mathrm{Au}$ terme de ces trente ans, et selon les vœux de la génération future, le capital pourra être réparti entre la Confédération et les cantons ou pourra être conservé et continuer de générer de nouveaux revenus. Ces propositions ont été favorablement accueillies par le Conseil fédéral, qui reconnaît qu'elles constituent «une solution simple, équilibrée et solidaire ${ }^{80}$.

S'appuyant sur ces propositions, le Conseil fédéral a remis au Parlement, le 28 février 2001, son message relatif à l'initiative populaire de l'UDC ${ }^{81}$, en lui recommandant de la rejeter. Ce rejet est motivé principalement par les raisons suivantes: cette initiative vise ouvertement à empêcher la création de la FSS;

79. Conseil fédéral, «Message concernant l'utilisation des réserves d'or et une loi fédérale sur la Fondation Suisse solidaire», 17.5.00, Feuille fédérale 2000, pp. 3664-3703 (message 00.042).

80. DFF, La Commission de l'économie et des redevances du Conseil des Etats soutient la Fondation Suisse solidaire, communiqué de presse, 2.2.01.

81. Conseil fédéral, «Message relatif à l'initiative populaire "pour le versement au fonds AVS des réserves d'or excédentaires de la Banque nationale suisse (initiative sur l'or)" », 28.2.01, Feuille fédérale 2001, pp. 1311-1330 (message 01.020). 
pour être trop vaguement formulée, elle pourrait porter atteinte à l'indépendance de la BNS; elle ne tient pas compte des droits des cantons et de la Confédération sur les bénéfices de la BNS; enfin, elle ne permet pas de résoudre les questions structurelles du financement de l'AVS.

Lors de sa session d'été, le 20 juin 2001, le Conseil des Etats a rejeté clairement l'initiative sur l'or et approuvé à une large majorité la création de la FSS, de même que son mode de financement selon la répartition du produit de la vente des réserves d'or excédentaires de la BNS proposée par la CER-E. L'adoption de la FSS par le Conseil des Etats, qui concrétise ainsi encore davantage le contre-projet à l'initiative sur l'or, a notamment été saluée par la Communauté de travail ${ }^{82}$.

Dans sa session d'automne, les 25 et 26 septembre 2001, le Conseil national a décidé, à son tour, de recommander le rejet de l'initiative sur l'or et de lui opposer le contre-projet déjà soutenu par le Conseil des Etats en juin (incluant le projet de FSS).

\section{SOURCES}

Site du projet de FSS : <www.solidarity.admin.ch >.

Dossier du Parlement fédéral sur les réserves d'or (FSS et initiative sur l'or) : <www.parlement.ch/F/ Gold/Gold_f.html>.

Dossier du Département fédéral des finances sur la FSS et les réserves d'or: <www.efd.admin.ch/f/ aktuell/gold/index.htm>.

\subsection{COUR PÉNALE INTERNATIONALE ET RATIFICATION DU STATUT DE ROME PAR LA SUISSE}

Le 17 juillet 1998, la Conférence diplomatique, réunie à Rome, a adopté, par 120 voix contre 7 et 21 abstentions, le Statut de la Cour pénale internationale. Kofi Annan, secrétaire général de l'ONU, a salué l'événement en déclarant que "la création de la Cour est un gage d'espoir pour les générations futures». Un peu partout, on considère même que la Cour est l'organisation internationale la plus importante depuis la fondation des Nations Unies. Le Statut de Rome marque de toute évidence l'avènement d'une ère nouvelle en droit pénal international et une étape importante sur la voie vers le respect des droits de l'homme et du droit international humanitaire. La Cour débutera probablement ses activités en 2002.

Ce chapitre commence par présenter les principaux aspects de cette nouvelle institution, puis il adopte un point de vue suisse pour se pencher de plus près sur la ratification du Statut de Rome et sur son application par la Suisse.

\subsubsection{LA COUR PÉNALE INTERNATIONALE}

\section{$\square$ Historique}

Jusqu'ici, le génocide, les crimes contre l'humanité et les crimes de guerre sont souvent restés impunis et certains Etats ou régions connaissent même une véritable culture de l'impunité. C'est à cette impunité qu'il s'agit de mettre un

82. Communauté de travail, La Fondation Suisse solidaire a passé le cap des lamentations, communiqué de presse, 20.06.01. 
terme. Le Tribunal de Nuremberg avait déjà reconnu que «les violations du droit international sont perpétrées par des hommes et non pas par des êtres abstraits, et que seule la condamnation des auteurs de ces violations garantira le respect des dispositions du droit international ${ }^{83}$.

Il a pourtant encore fallu attendre longtemps avant qu'une cour pénale internationale et permanente ne voie le jour. La guerre froide et les craintes des Etats d'abandonner une portion de souveraineté ont entravé la réalisation de l'idée, émise vers la fin du XIX ${ }^{\mathrm{e}}$ siècle déjà, qui visait à créer une cour pénale internationale et, surtout, permanente; qualité qui lui permettrait d'échapper aux visées opportunistes de différentes puissances ${ }^{84}$. Au vu des atrocités commises pendant la Seconde Guerre mondiale, les puissances victorieuses ont certes institué les tribunaux de Nuremberg et de Tokyo. Ces deux premiers tribunaux pénaux internationaux ne pouvaient cependant poursuivre et juger que les crimes commis par les perdants. De même, la compétence des tribunaux pour l'ex-Yougoslavie et pour le Rwanda est limitée dans l'espace et dans le temps, c'est-à-dire à un conflit précis et à une région déterminée. Ces divers tribunaux ad hoc ont néanmoins contribué à l'essor du droit pénal international.

Les tribunaux institués pour juger les crimes perpétrés en ex-Yougoslavie et au Rwanda ont en effet démontré qu'il est possible d'appliquer une justice pénale internationale tout en respectant les grands principes du droit. Leurs activités ont donné un nouvel élan aux efforts entamés en 1989 dans le cadre de l'Assemblée générale de l'ONU en vue de créer une cour pénale internationale (bien que l'idée eût été jugée utopique quelques années auparavant). C'est ainsi que le Statut de Rome a pu être adopté le 17 juillet 1998, au terme de longues négociations dont le mérite revient pour beaucoup au groupe dit des «Etats pilotes». Même les organisations non gouvernementales (ONG) ont qualifié l'issue des négociations de positive et d'historique.

\section{$\square$ Le Statut de Rome en bref}

En adoptant le Statut de Rome, les Etats ont affirmé que «les crimes les plus graves qui touchent l'ensemble de l'humanité ne sauraient rester impunis et que leur répression doit être effectivement assurée par des mesures prises dans le cadre national et par le renforcement de la coopération internationale» (préambule du Statut). Contrairement à tous les tribunaux pénaux internationaux mis sur pied jusqu'alors, la Cour pénale internationale est une institution permanente. Son existence se fonde sur un accord de droit international, le Statut de Rome, dont les 128 articles ne sont contraignants que pour les Etats ayant ratifié l'accord. Dès l'entrée en vigueur du Statut de Rome - fixée après que 60 Etats l'auront ratifié -, la Cour pénale internationale pourra exercer sa compétence juridictionnelle sur les individus qui se sont rendus coupables d'un génocide, d'un crime contre l'humanité ou d'un crime de guerre.

Les quatre organes de la Cour pénale internationale, dont le siège est à La Haye, comprennent la Présidence, les sections judiciaires (Section des appels, Section de première instance et Section préliminaire), le Bureau du Procureur et le

83. The Trial of the Major War Criminals: Proceedings of the International Military Tribunal sitting at Nürnberg, Germany, 14 November 1945-1 October 1946, 30 septembre 1946, p. 465.

84. Le Suisse Gustave Moynier a proposé, en 1872 déjà, la création d'une autorité judiciaire internationale chargée de poursuivre sur le plan pénal les violations de la Convention de Genève de 1864. 
Greffe. Les activités de la Cour pénale internationale sont soumises au contrôle de l'Assemblée des Etats parties, qui se réunit au moins une fois l'an.

Le Statut de Rome est un traité complexe qui innove dans nombre de domaines. En effet, il ne se contente pas de créer une nouvelle institution dotée de sa propre organisation judiciaire mais va beaucoup plus loin: il dresse une liste aussi complète que possible de violations - très mal définies jusqu'alors - du droit international public, pose les principes généraux du droit international, crée un nouveau droit de la procédure pénale internationale, fournit des directives rudimentaires pour l'exécution des peines et engage les Etats signataires à coopérer avec la Cour pénale internationale, coopération qui comprend même le transfèrement d'auteurs présumés.

\section{$\square$ Compétence de la Cour pénale internationale et déclenchement de la procédure}

L'entrée en vigueur du Statut de Rome confère à la Cour pénale internationale permanente la compétence de poursuivre, sur le plan pénal, les individus qui se sont rendus coupables d'un génocide, d'un crime contre l'humanité ou d'un crime de guerre. La juridiction de la Cour ne s'étend toutefois pas aux Etats ni aux autres personnes morales telles que les entreprises multinationales ou les organismes transnationaux ${ }^{85}$.

Pour que la Cour puisse exercer sa juridiction, l'une des deux conditions ciaprès doit être remplie: la violation du droit international en cause a été commise sur le territoire d'un Etat partie au Statut de Rome (principe de la territorialité) ou alors cette violation est le fait d'un ressortissant d'un Etat partie (principe de la personnalité active). Les Etats non parties au Statut peuvent également reconnaître la juridiction de la Cour pour une situation spécifique (compétence $a d h o c$ ).

La poursuite pénale des crimes définis dans le Statut relève néanmoins en priorité de la compétence et de la responsabilité des instances pénales nationales. Le droit international oblige même les Etats à poursuivre ces crimes ou du moins certains de ces crimes. Cette obligation s'applique également aux crimes commis dans un autre pays, c'est-à-dire lorsque le coupable et la victime ne sont pas des ressortissants de l'Etat appelé à juger (principe dit de l'universalité du droit). La juridiction de la Cour pénale internationale se fonde sur la complémentarité; autrement dit, la Cour est compétente pour traiter un cas uniquement lorsque aucun Etat n'a la capacité ou la volonté de mener une véritable enquête pénale $^{86}$. La Cour pénale internationale n'est donc nullement une instance de recours. De plus, elle ne vise en aucun cas à remplacer la juridiction pénale nationale, mais à la compléter lorsqu'elle est déficiente.

\section{$\square$ Les crimes définis dans le Statut de Rome}

Dès l'entrée en vigueur du Statut de Rome, la Cour pénale internationale exercera sa compétence à l'égard des «crimes majeurs» relevant du droit international

85. Cf. par exemple Andrew Clapham, «The Question of Jurisdiction under International Criminal Law over Legal Persons: Lessons from the Rome Conference on the International Criminal Court», in Menno Kamminga et Saman Zia-Zarifi (ed.), Liability of Multinational Corporations under International Law, The Hague; Boston (Mass.): Kluwer Law International, 2000, p. 139.

86. Article 17 du Statut de Rome. 
public: génocide, crime contre l'humanité et crime de guerre. Pour que sa compétence s'étende également aux crimes d'agression, les Etats parties devront tout d'abord convenir d'une définition de ce crime ainsi que des conditions dans lesquelles devra s'inscrire la juridiction de la Cour $^{87}$.

Conformément à la Convention sur le génocide de 1948, l'article 6 du Statut de Rome définit le génocide comme un ou plusieurs actes commis dans l'intention de détruire, en tout ou en partie, un groupe national, ethnique, racial ou religieux. Voici le ou les actes en question: meurtre de membres du groupe; atteinte grave à l'intégrité physique ou mentale de membres du groupe; soumission intentionnelle du groupe à des conditions d'existence devant entraîner sa destruction physique totale ou partielle; mesures visant à entraver les naissances au sein du groupe; transfert forcé d'enfants du groupe à un autre groupe.

Le Statut de Rome est par ailleurs le premier traité multilatéral qui définit avec une relative précision les crimes contre l'humanité. L'article 7 du Statut énumère ainsi les actes suivants comme étant constitutifs d'un crime contre l'humanité: meurtre; extermination; réduction en esclavage; déportation ou transfert forcé de population; emprisonnement ou autre forme de privation grave de liberté physique; torture, viol, esclavage sexuel, prostitution forcée, grossesse forcée, stérilisation forcée ou toute autre forme de violence sexuelle; persécution de tout groupe ou de toute collectivité identifiable pour des motifs d'ordre politique, racial, national, ethnique, culturel, religieux ou sexiste, ou en fonction d'autres critères; disparitions forcées de personnes; crime d'apartheid; et autres actes inhumains de caractère analogue. L'article précise que ces actes ne constituent un crime contre l'humanité que «lorsqu'ils sont commis dans le cadre d'une attaque généralisée ou systématique lancée contre une population civile et en connaissance de cette attaque». Par «attaque lancée contre une population civile», le Statut entend une répétition des actes énumérés ci-dessus contre une population civile, en application ou dans la poursuite de la politique d'un Etat ou d'une organisation.

Les crimes de guerre sont des infractions graves au droit international humanitaire qui s'applique en cas de conflit armé international ou interne, tel qu'il ressort notamment des quatre Conventions de Genève de 1949. L'article 8 du Statut de Rome comprend ici une liste (quelque peu confuse) de 50 éléments constitutifs d'un crime de guerre. A titre d'exemple, on peut citer les actes suivants lorsqu'ils sont commis dans le cadre d'un conflit armé: le fait de diriger intentionnellement des attaques contre la population civile ou contre des biens de caractère civil ; le fait d'occasionner des dommages «collatéraux» disproportionnés à la population ou à des biens civils ; l'utilisation de certaines armes chimiques ou biologiques; la torture et les traitements inhumains infligés aux prisonniers de guerre ou à d'autres personnes protégées; le viol et toute autre forme de violence sexuelle; le recrutement ou le recours à des enfants soldats; l'installation par une puissance occupante d'une partie de sa population civile dans le territoire qu'elle occupe.

\section{$\square$ Principes généraux du droit pénal international}

Le chapitre 3 du Statut de Rome définit des principes généraux du droit pénal international que la Cour pénale internationale est tenue de respecter. La qualité

87. Article $5,2^{\mathrm{e}}$ alinéa du Statut de Rome. 
officielle de chef d'Etat ou de gouvernement, de membre d'un gouvernement ou d'un parlement, n'exonère ainsi en aucun cas de la responsabilité pénale au regard de la Cour; les éventuelles immunités qui peuvent s'attacher à la qualité officielle d'une personne n'empêchent pas la Cour d'exercer sa compétence envers cette personne ${ }^{88}$. Un autre principe général prévoit que le fait qu'un crime a été commis sur ordre d'un gouvernement ou d'un supérieur n'exonère pas la personne qui l'a commis de sa responsabilité pénale ${ }^{89}$.

\section{$\square$ Procédure}

Le Statut de Rome donne une description relativement détaillée de la procédure devant la Cour pénale internationale. Le règlement de cette procédure est le produit d'une fusion entre divers systèmes juridiques, notamment de la common law et de la civil law, dans l'objectif de résoudre les problèmes particuliers à une procédure devant la Cour.

La procédure devant la Cour pénale internationale peut être engagée par un Etat partie, par le Conseil de sécurité des Nations Unies ou par le Procureur (indépendant) lui-même ${ }^{90}$. Cette dernière possibilité traduit un succès notable remporté par les organisations non gouvernementales. Le Procureur peut en effet recueillir des informations auprès d'organisations non gouvernementales ou auprès de particuliers et en tenir compte. Pour poursuivre ses investigations formelles, il doit cependant requérir l'accord de la Chambre préliminaire. Par ailleurs, la phase cruciale du déclenchement de la procédure et du transfert de compétence des instances nationales à la Cour pénale internationale comprend plusieurs verrous de sécurité, dont le principal objectif est de garantir le respect du principe de complémentarité ${ }^{91}$. Les décisions de la Chambre de première instance peuvent faire l'objet d'un appel auprès de la Chambre d'appel. Le Statut de Rome garantit en outre les droits de l'accusé conformément aux normes internationales et contraint la Cour pénale internationale à prendre les mesures appropriées pour protéger les témoins et les victimes ${ }^{92}$. Le Statut donne enfin la possibilité à la Cour d'accorder des réparations aux victimes, des réparations qui peuvent prendre la forme d'une restitution, d'une indemnisation ou d'une réhabilitation ${ }^{93}$.

\section{Coopération internationale et exécution des peines}

Puisque la Cour pénale internationale ne possède aucun service de police et qu'elle n'est en règle générale pas habilitée à procéder elle-même à des investigations sur le territoire des Etats parties, l'efficacité des poursuites qu'elle mène dépend donc largement de la coopération avec les Etats concernés. L'obligation, stipulée avant tout dans le chapitre 9 du Statut de Rome, des Etats parties de collaborer avec la Cour est donc primordiale. Sur demande de la Cour, les Etats parties sont par exemple tenus d'arrêter les auteurs présumés de crimes et de les remettre à la Cour, d'aider la Cour à rassembler et à préserver des éléments de preuve, de mettre des documents à disposition, d'examiner des localités ou des

88. Article 27 du Statut de Rome.

89. Article 33 du Statut de Rome.

90. Article 13 du Statut de Rome.

91. Articles 15 et 17-20 du Statut de Rome.

92. Articles 67 et 68 du Statut de Rome.

93. Articles 75 et 79 du Statut de Rome. 
sites (notamment des sépultures), de rechercher et de saisir des objets, d'identifier et de localiser des biens et des avoirs pour les geler, les saisir et/ou les confisquer ${ }^{94}$. Un Etat peut cependant rejeter une demande d'assistance de la Cour lorsque la divulgation d'informations ou de documents risque, selon lui, de porter atteinte à sa sécurité nationale ${ }^{95}$. L'exécution des peines prononcées par la Cour pénale internationale - emprisonnement, amende ou confiscation incombe également aux Etats parties. La Cour conserve néanmoins sa compétence formelle et exerce un rôle de surveillance sur l'exécution ${ }^{96}$.

\subsubsection{LA SUISSE ET LA COUR PÉNALE INTERNATIONALE}

\section{$\square$ Participation de la Suisse aux négociations visant à créer la Cour pénale internationale}

Les autorités suisses ont d'emblée mesuré l'importance du projet visant à créer une Cour pénale internationale permanente et ont, dès le départ, pris une part active aux négociations allant dans ce sens. Elles considéraient et considèrent en effet qu'il était de leur devoir d'appuyer ces efforts puisque la politique extérieure traditionnellement menée par la Suisse cherche à promouvoir le droit international humanitaire et le respect des droits de l'homme ${ }^{97}$. La Suisse a ainsi joué un rôle essentiel pendant les négociations ${ }^{98}$, notamment en tant que membre fondateur du groupe des «Etats pilotes» (like-minded states), qui se sont attachés à promouvoir une Cour pénale indépendante et dotée d'un maximum de compétences. Lors de la définition des crimes, la Suisse a surtout œuvré pour que le texte en préparation ne revienne pas en arrière sur les dispositions du droit international public déjà en vigueur. Ses efforts ont d'ailleurs été couronnés de succès, puisque le texte qui précise les éléments constitutifs d'un crime de guerre reprend en majeure partie le projet de texte soumis par la Suisse à la Commission préparatoire. Par ailleurs, tant les ONG que les Etats ont reconnu et reconnaissent l'effort constructif fourni par la Suisse.

\section{$\square$ Ratification et application du Statut de Rome}

\section{Position de l'administration fédérale}

La Suisse a signé le Statut de Rome dès le lendemain de son adoption, le 18 juillet 1998, car elle a jugé que les négociations avaient débouché sur un résultat positif et que le Statut constitue une base solide pour promouvoir les droits de l'homme et le droit international humanitaire ${ }^{99}$. Eu égard à la tradition

94. Voir avant tout les articles 86, 89 sqq., 93 et 109 du Statut de Rome.

95. Article 72 du Statut de Rome.

96. Articles 103 sqq. et 109 du Statut de Rome.

97. Du point de vue constitutionnel, l'appui apporté à la création de la Cour pénale internationale correspond aux termes de l'article 2, 4e alinéa, de la Constitution, dans lequel la Confédération «s'engage en faveur d'un ordre international juste et pacifique», ainsi qu'à l'article $54,2^{\mathrm{e}}$ alinéa, qui prévoit que la Confédération doit s'attacher à promouvoir le respect des droits de l'homme.

98. Bien que le projet de créer une Cour pénale internationale ait été lancé dans le cadre de l'Assemblée générale des Nations Unies et que l'Assemblée générale ait ensuite grandement contribué à sa réalisation, la Suisse a, la plupart du temps, participé aux négociations comme un partenaire à part entière, car les Etats ont décidé de fonder l'existence de la Cour sur un traité international et non pas sur une résolution de l'Assemblée générale ou du Conseil de sécurité des Nations Unies.

99. Lire également le compte rendu de Lucius Caflisch, chef de la délégation suisse à la Conférence de Rome, in Liechtensteinische Juristen-Zeitung, 1, 1999, notamment pp. 10-11. 
humanitaire de la Suisse et à sa qualité d'Etat dépositaire des Conventions de Genève, la Confédération ne pouvait ensuite que ratifier le Statut de Rome ${ }^{100}$.

Pour pouvoir participer à la première - et très importante - Assemblée des Etats parties après l'entrée en vigueur du Statut de Rome, le Conseil fédéral a tout mis en œuvre pour que la ratification suisse intervienne aussi rapidement que possible ${ }^{101}$. A cet effet, il s'est contenté, dans un premier temps, d'élaborer les bases légales introduisant l'obligation de collaborer avec la Cour pénale internationale. Dans un deuxième temps, soit après la ratification, le Conseil fédéral présentera des propositions pour introduire les éléments constitutifs de crimes selon le Statut de Rome dans le droit pénal suisse, car les mesures d'exécution du Statut ne contiennent pas de clause contraignante à ce sujet ${ }^{102}$.

Le 22 juin 2001, l'Assemblée fédérale a ainsi pu adopter les mesures législatives indispensables à l'exécution des obligations découlant du Statut de Rome. Les voici ${ }^{103}$ :

Loi fédérale sur la coopération avec la Cour pénale internationale ${ }^{104}$;

- Loi fédérale portant modification du code pénal et du code pénal militaire (Infractions aux dispositions sur l'administration de la justice devant les tribunaux internationaux; modification de l'article $309 \mathrm{CP}$ et adjonction de l'article 179, lettre b, CPM) ${ }^{105}$.

A ces deux textes vient s'ajouter l'arrêté fédéral relatif à l'approbation du Statut de Rome de la Cour pénale internationale, qui rend la ratification possible ${ }^{106}$. Par ailleurs, la Cour pénale internationale n'étant pas une communauté supranationale au sens de l'article 140, 1 $1^{\text {er }}$ alinéa, lettre b, de la Constitution fédérale, la ratification n'était pas soumise au référendum obligatoire ${ }^{107}$. Il restait cependant à déterminer si l'obligation de remettre à la Cour pénale internationale des citoyens suisses soupçonnés d'avoir commis un génocide, un crime contre l'humanité ou un crime de guerre, mais n'ayant pas fait l'objet de poursuites pénales, était compatible avec la disposition constitutionnelle qui interdit la remise de citoyens suisses à une autorité étrangère sans leur consentement $^{108}$, et s'il était nécessaire, le cas échéant, de modifier la Constitution. Le Conseil fédéral a conclu qu'il existe une différence fondamentale entre la remise d'un Suisse ou d'une Suissesse à la Cour pénale internationale, d'une part, et la remise d'un Suisse ou d'une Suissesse aux autorités d'un autre Etat, d'autre part, de sorte que l'interdiction inscrite dans la Constitution ne s'applique pas ici. Il a également indiqué que si la remise d'un citoyen à la Cour

100. Voir Message du Conseil fédéral relatif au Statut de Rome, Feuille fédérale (FF), 2001, pp. 359-536. 101. Ibid., pp. 361 et 419; Michael Cottier, "The Case of Switzerland», in Claus Kress et Flavia Lattanzi (Eds.), The Rome Statute and Domestic Legal Orders, vol. I, General Aspects and Constitutional Issues, Baden-Baden: Nomos, 2000, pp. 219-220 et 224 sqq. Pour ce qui est des compétences de l'Assemblée des Etats parties, voir ci-dessous point 5.6.3.

102. Voir ci-dessous point «Elaboration d'une juridiction suisse portant sur les crimes définis dans le Statut de Rome».

103. La législation d'application entrera en vigueur dès le moment où le Statut de Rome deviendra applicable pour la Suisse, soit très probablement encore dans le courant de 2002.

104. FF 2001, p. 2748.

105. FF 2001, p. 2768.

106. FF 2001, p. 2801.

107. Voir à ce sujet Michael Cottier, article cité, pp. 222-223.

108. Article 25, alinéa $1^{\text {er }}$, Constitution fédérale. 
pénale internationale restreint bel et bien les droits fondamentaux de la personne, les conditions de cette restriction peuvent être inscrites dans une loi (conformément à l'article 36 de la Constitution) et qu'une modification de la Constitution ne s'impose dès lors pas ${ }^{109}$.

La Suisse a non seulement participé à l'élaboration du Statut de Rome et de son règlement de procédure, en conformité avec les normes internationales, mais pourra aussi continuer à veiller au bon fonctionnement de la Cour pénale internationale en participant pleinement à l'Assemblée des Etats parties. En le ratifiant, la Suisse a par ailleurs intégré le Statut de Rome dans sa propre législation, mais il convient de souligner ici que les dispositions du Statut ne visent que les crimes les plus graves, qui concernent l'ensemble de la communauté internationale, et que la Cour n'est compétente que si la Suisse n'engage pas elle-même des poursuites pénales contre les coupables ${ }^{110}$.

En définitive, les lois fédérales portant application du Statut de Rome et l'arrêté fédéral relatif à son approbation équivalent à une adhésion à une organisation internationale, de sorte qu'ils étaient uniquement soumis au référendum facultatif ${ }^{111}$. Le délai référendaire ayant expiré le 11 octobre 2001 sans que quiconque ait déposé un référendum, la Suisse a ratifié le Statut de Rome le 12 octobre $2001^{112}$.

\section{Obligation de coopérer avec la Cour pénale internationale}

En ratifiant le Statut de Rome, les Etats parties s'engagent à coopérer avec la Cour pénale internationale en matière d'enquêtes et d'investigations pénales ${ }^{113}$. Les Etats doivent donc veiller à élaborer à cet effet les normes légales nationales et les règlements de procédures qui s'imposent.

Pour coordonner la coopération dans les différents domaines, la loi sur la coopération avec la Cour pénale internationale prévoit la création d'un service central au sein de l'Office fédéral de la justice. Ce service statue, dans chaque cas, sur la recevabilité et sur les modalités de la coopération requise, arrête les mesures nécessaires et désigne le canton ou l'autorité fédérale qui sera en l'occurrence concrètement chargé de la coopération. Il remet les personnes poursuivies à la Cour, il lui transmet également les résultats d'enquêtes, recouvre les amendes et statue sur les demandes de la Cour de prendre en charge l'exécution des peines. Les décisions finales du service central peuvent faire l'objet d'un recours de droit administratif au Tribunal fédéral.

La loi fédérale régit par ailleurs les modalités de la remise et de la détention aux fins de remise - par exemple les questions relevant du droit d'être entendu des personnes poursuivies ou condamnées par la Cour. La loi fixe également les principes qui régissent les autres formes de la coopération, notamment les points suivants: interrogatoire et citation à comparaître, actes d'instruction

109. Message du Conseil fédéral relatif au Statut de Rome, message cité, pp. 451-452.

110. Voir Michael Cottier, «Verfassungsrechtliche Aspekte der schweizerischen Ratifizierung des Römer Statuts», Schweizerische Zeitschrift für Strafrecht (également pour ce qui est d'autres problèmes de compatibilité du Statut de Rome avec la Constitution fédérale). En ce qui concerne les avis divergents de représentants de l'UDC, voir ci-dessous, point «Prise de position d'intervenants n'appartenant pas à l'administration fédérale ».

111. Article 141, alinéa $1^{\text {er }}$, lettre d, chiffre 2, Constitution fédérale.

112. DFAE, communiqué de presse concernant l'adhésion à la Cour pénale internationale, 12.10.01.

113. Voir ci-dessus point «Coopération internationale et exécution des peines». 
conduits à titre exceptionnel par le Procureur de la Cour sur le territoire de la Confédération, transmission d'éléments de preuve, saisie d'objets ou d'avoirs en relation avec les actions punissables et remise de ces objets ou avoirs à la Cour en vue de leur confiscation éventuelle, affectation au Fonds au profit des victimes ou restitution aux victimes ou aux personnes lésées.

L'arrêté fédéral relatif à l'approbation du Statut de Rome et la loi fédérale sur la coopération avec la Cour pénale internationale prévoient de plus que la Suisse peut prendre en charge une personne condamnée à une peine d'emprisonnement par la Cour, pour autant que cette personne soit un ressortissant suisse ou réside habituellement en Suisse. Il est regrettable que la prise en charge de l'exécution des peines se limite aux citoyens suisses et aux personnes résidant en Suisse, car il est probable que la Cour sera régulièrement confrontée à des situations dans lesquelles une personne condamnée ne pourra pas purger sa peine dans son pays d'origine, soit parce qu'elle serait immédiatement libérée, soit parce qu'elle ne bénéficierait pas de toute la sécurité nécessaire. La Confédération a manqué ici l'occasion d'élaborer des dispositions plus en rapport avec notre qualité d'Etat dépositaire des Conventions de Genève et avec la politique étrangère de la Suisse.

\section{Elaboration d'une juridiction suisse portant sur les crimes définis dans le Statut de Rome}

Comme nous l'avons déjà dit, la partie exécutoire du Statut de Rome ne contraint pas expressément les Etats parties à élaborer une juridiction nationale portant sur les crimes définis dans le Statut. Le sixième paragraphe du préambule de ce Statut n'en rappelle pas moins qu' «il est du devoir de chaque Etat de soumettre à sa juridiction criminelle les responsables de crimes internationaux». Ce préambule réaffirme aussi qu'il incombe à chaque Etat de poursuivre sur le plan pénal les crimes extrêmement graves que sont le génocide, le crime contre l'humanité et le crime de guerre ${ }^{114}$. Par ailleurs, en ratifiant certaines conventions internationales, la Suisse s'est engagée à poursuivre certains crimes contre l'humanité. C'est le cas notamment des violations graves des Conventions de Genève de 1949 et de leur premier Protocole additionnel de 1977, ainsi que des actes de torture conformément à la Convention contre la torture de 1984. Enfin, au vu du principe de complémentarité, la Suisse a tout intérêt à intégrer les différents crimes du Statut de Rome dans sa propre juridiction, car elle risquerait, en l'absence d'une juridiction suffisante, de devoir remettre ses propres citoyens à la Cour.

Aujourd'hui déjà, l'absence de dispositions explicites dans le code pénal militaire permet de poursuivre les crimes de guerre, au sens du droit international coutumier, en se fondant sur le principe de l'universalité du droit ${ }^{115}$. De plus, un nouvel article du code pénal, l'article 264, est entré en vigueur le 15 décembre 2000. Cet article accorde aux tribunaux suisses la compétence de juger un crime de guerre, quel que soit le lieu où il a été commis et quelle que soit la nationalité

114. Voir p. ex. K. Ambos, «Völkerrechtliche Bestrafungspflichten bei schweren Menschenrechtsverletzungen », Archiv des Völkerrechts, 1999, p. 318.

115. Article 2, 9e alinéa, et 108-114 CPM. Voir p. ex. Andreas R. Ziegler, «Domestic Prosecution and International Cooperation with Regard to Violations of International Humanitarian Law: The Case of Switzerland», Schweizerische Zeitschrift für Internationales und Europäisches Recht, 1997, p. 561 . 
du coupable et des victimes ${ }^{116}$. La Suisse ne possède cependant aucune juridiction concernant les crimes contre l'humanité en tant que tels. Ce domaine présente donc une lacune, que le législateur ferait bien de combler, car le droit pénal suisse ne tient pas du tout, ou pas suffisamment, compte de l'élément d'injustice caractéristique et de certains éléments constitutifs du crime contre l'humanité, voire dans certains cas du crime lui-même ${ }^{117}$.

Dès après la ratification du Statut de Rome, le Conseil fédéral entend donc soumettre à l'Assemblée fédérale un projet de loi visant à intégrer dans le droit pénal suisse les crimes définis dans le Statut et a déjà entrepris des travaux allant dans ce sens. Voici quelques-uns des points qu'il s'agit de régler:

$\square$ Comment définir les crimes tout en respectant les obligations qui découlent d'autres conventions et du droit international coutumier?

$\square$ Comment intégrer dans le droit pénal suisse les crimes du droit international public et les principes généraux du droit pénal correspondants?

- Comment répartir les compétences entre Confédération et cantons, et entre tribunaux civils et tribunaux militaires?

口 Comment régler les modalités du principe de l'universalité du droit (subsidiarité, immunités, application de la nouvelle législation également aux crimes qui relèvent du droit international coutumier et qui ont été commis avant l'entrée en vigueur de la nouvelle législation, p. ex.) ? ${ }^{118}$

\section{Prise de position d'intervenants n'appartenant pas à l'administration fédérale}

La création de la Cour pénale internationale, ainsi que l'adhésion de la Suisse à la Cour, ont bénéficié d'un large appui en Suisse, tant de la part de la société civile que des partis politiques. Les résultats de la procédure de consultation concernant la ratification du Statut de Rome et les projets de lois visant à le faire appliquer se sont ainsi révélés extrêmement positifs. A l'exception du Centre patronal, tous les organismes consultés ont salué la mise en place de la Cour pénale internationale de même que la ratification du Statut de Rome par la Suisse. Nombreux furent ceux qui ont jugé l'adoption du Statut comme un événement majeur et ont souligné l'effet dissuasif de l'existence même de la Cour. La Conférence des évêques suisses s'est par exemple déclarée satisfaite de la protection prévue pour les victimes et de la possibilité de leur accorder des répa-

116. Voir Message du Conseil fédéral relatif à la Convention pour la prévention et la répression du crime de génocide, et révision correspondante du droit pénal, FF 1999, p. 4911.

117. Pour en savoir plus sur la compétence des tribunaux suisses de juger les crimes qui violent le droit international public, voir Michael Cottier, «The Case of Switzerland», article cité, pp. 224 sqq. Pour ce qui est des lacunes de la législation suisse en matière de torture, voir idem, "Verfassungsrechtliche Aspekte der schweizerischen Ratifizierung des Römer Statuts ", article cité. Concernant les éventuelles modalités pour intégrer les crimes définis dans le Statut de Rome dans la législation allemande, voir Claus Kress, Vom Nutzen eines deutschen Völkerstrafgesetzbuchs, Baden-Baden: Nomos, 2000.

118. Voir Bilan de l'état d'avancement de la ratification et la mise en œuvre par la Suisse, Strasbourg: Conseil de l'Europe, Consult/ICC (2005) 25, 10 juillet 2001, <www.legal.coe.int/criminal/icc>. Pour une évaluation critique des nouvelles dispositions légales sur le génocide, voir Michael Cottier, «The Case of Switzerland», article cité, pp. 227 sqq. Voir également Message du Conseil fédéral relatif au Statut de Rome, message cité, pp. 361, 389-390, 418-420, 482-483, 506 (et 466-467); Message du Conseil fédéral relatif à la Convention pour la prévention et la répression du crime de génocide, et révision correspondante du droit pénal, message cité. 
rations, tandis que l'Université de Lausanne a regretté que la compétence de la Cour ne s'étende pas aux personnes morales. Le projet a notamment bénéficié de l'appui inconditionnel des organisations de défense des droits de l'homme qui ont pris part à la procédure de consultation. Même l'UDC a salué la création et l'esprit de la Cour, en se demandant si celle-ci allait être à la hauteur de son idéal. Nombre d'organismes consultés ont en outre loué le rôle actif joué par la Suisse pendant les négociations multilatérales ${ }^{119}$.

La grande majorité des organismes consultés, des partis politiques et des parlementaires s'est ralliée à la position du Conseil fédéral, selon laquelle l'éventuelle obligation de remettre un Suisse ou une Suissesse à la Cour pénale internationale n'équivaut pas à une extradition de citoyens suisses et qu'une modification de la Constitution ne s'imposait donc pas ${ }^{120}$. L'UDC n'était cependant pas du même avis. C'est pourquoi le conseiller national Ulrich Schlüer a demandé, au nom du groupe parlementaire UDC, que l'adhésion au Statut de Rome soit soumise au référendum obligatoire ${ }^{121}$. Le groupe parlementaire UDC a également remis en cause le fait de confier à un service gouvernemental (le service central prévu dans le projet de loi), et non à un tribunal, le soin d'entretenir des contacts avec la Cour pénale internationale. Ce même groupe a par ailleurs émis des réserves sur la possibilité accordée à la Cour de modifier une plainte, même après que le coupable présumé lui a été remis, possibilité qui n'existe pas dans le cadre de l'extradition ${ }^{122}$.

Au Conseil national, l'adhésion à la Cour pénale internationale a été adoptée par 135 voix contre 26 lors des délibérations et par 181 voix contre 8 lors du votre final, sans que cette adhésion soit soumise au référendum obligatoire ${ }^{123}$. Quant au Conseil des Etats, il a approuvé à l'unanimité la ratification du Statut de Rome et son intégration dans la législation suisse $\mathrm{e}^{124}$.

Contrairement aux groupements apparus dans nombre d'autres pays, aucune coalition nationale des ONG pour la Cour pénale internationale n'a vu le jour en Suisse, du moins pas jusqu'ici. Il y a sans doute deux raisons à cela: d'une part, les idées et les intérêts que la Suisse a fait valoir lors des négociations, de même que l'application prévue du Statut de Rome dans notre pays, rejoignent dans une large mesure les objectifs des organisations les plus influentes de défense des droits de l'homme; d'autre part, l'effort de compréhension

119. Voir EDA, Direktion für Völkerrecht, Zusammenfassung der Vernehmlassungsergebnisse vom 15. November 2000, Römer Statut des Internationalen Strafgerichtshofs, Bundesgesetz über die Zusammenarbeit mit dem Internationalen Strafgerichtshof und Revision des Strafrechts (résumé des résultats de la procédure de consultation relative au Statut de Rome).

120. Ibid, pp. 7-8; Bulletin officiel (BO) CN (Conseil national) 2001, pp. 156-164 et 954-955; BO CE (Conseil des Etats) 2001, pp. 465-469 et 475. Trois experts sont parvenus à la même conclusion, voir p. ex. BO CN 2001, pp. 157 et 161 ; BO CE 2001, p. 467.

121. BO CN 2001, pp. 158-159. Lors de la procédure de consultation, l'UDC et le canton d'Argovie s'étaient déjà prononcés en faveur d'une modification de la Constitution. Zusammenfassung der Vernehmlassungsergebnisse vom 15. November 2000 ..., op. cit., pp. 7-8.

122. BO CN 2001, p. 158. L'UDC a également critiqué le fait qu'il est possible, sur demande de la Cour, de garder une personne jusqu'à soixante jours en détention sans lui faire connaître les motifs de la plainte. Le conseiller fédéral Deiss a très justement rétorqué que cet argument était erroné. $\mathrm{BO} \mathrm{CN}$ 2001 , pp. 158 et 162-163.

123. BO CN 2001, p. 164, et BO CN 2001, p. 955.

124. BO CE 2001, pp. $465-469$ et 475. 
mutuelle qui a marqué les négociations de Rome et de New York s'est révélé extrêmement constructif. Par ailleurs, suite à un arrêté du Conseil fédéral, un représentant de la société civile a été admis au sein de la délégation suisse envoyée à la Conférence diplomatique de Rome. Il était aussi apparu comme vraisemblable que la grande majorité de la population suisse allait soutenir le projet.

\subsubsection{PERSPECTIVES}

Le Statut de Rome entrera en vigueur lorsque 60 Etats l'auront ratifié. Après la ratification finale de la Suisse, le 12 octobre 2001, les Etats ayant adhéré au Statut étaient déjà au nombre de 43, et à fin mars 2002, de 56. On peut donc s'attendre à ce que l'entrée en vigueur intervienne en 2002.

Il reste néanmoins encore beaucoup à faire, aussi bien avant qu'après l'entrée en vigueur, pour permettre à la Cour pénale internationale de commencer ses activités sans retard et pour assurer le succès de cette nouvelle institution. Depuis 1999, la Commission préparatoire, qui s'active au siège de l'ONU à New York, examine des propositions de plusieurs «instruments complémentaires » à l'intention de la $1^{\text {re }}$ Assemblée des Etats parties. Parmi ces instruments, il convient de citer ceux qui ont déjà été adoptés le 30 juin 2000 et le 5 octobre 2001 : projets d'éléments constitutifs des crimes; règlement de procédure et administration de la preuve; accord sur les rapports avec les Nations Unies; règlement financier; accord sur les prérogatives et sur les immunités de la Cour pénale internationale; règlement interne de l'Assemblée des Etats parties; accord de siège provisoire, n'ayant pas encore fait l'objet de négociations préalables, à conclure avec les Pays-Bas; budget provisoire de la première année de fonctionnement et, bien entendu, entente sur la compétence de la Cour à juger les crimes d'agression ${ }^{125}$.

Dès après l'entrée en vigueur du Statut de Rome, la $1^{\text {re }}$ Assemblée des Etats parties se penchera sur ces projets et, le cas échéant, les adoptera, avec ou sans modifications. Cette première assemblée élira par ailleurs les juges, le Procureur et les membres du Bureau de l'Assemblée des Etats parties. Elle fera également part d'éventuelles recommandations quant au choix du Chancelier.

Lorsque tout sera en place, l'Assemblée des Etats parties devra se réunir au moins une fois l'an et assumer une importante charge administrative. Ses attributions comprennent en effet les points suivants: exercer une surveillance sur les activités de la Cour pénale internationale et de ses organes; examiner les rapports et les activités du Bureau de l'Assemblée; arrêter le budget de la Cour; examiner toute question relative à la non-coopération des Etats et d'autres tâches encore ${ }^{126}$. Le Statut de Rome prévoit aussi la tenue de conférences de révision, dont la première sera convoquée sept ans après l'entrée en vigueur du Statut $^{127}$. La Conférence de Rome avait d'ailleurs recommandé qu'une telle conférence de révision examine également la possibilité d'étendre la compétence de la Cour aux actes de terrorisme et aux crimes liés à la drogue ${ }^{128}$.

125. Consulter <www.un.org/icc >.

126. Article 112 du Statut de Rome.

127. Article 123 du Statut de Rome.

128. Résolution E, Annexe 1 de l'Acte final de la Conférence diplomatique de plénipotentiaires des Nations Unies sur la création d'une Cour pénale internationale, Rome, le 17 juillet 1998. Il n'en reste pas moins que l'on peut également considérer l'attaque terroriste contre le World Trade Center comme un crime contre l'humanité, conformément à l'article 7 du Statut de Rome. 
Les Etats sont par ailleurs invités à créer les bases légales nécessaires à leur coopération avec la Cour, par exemple pour ce qui est de la poursuite pénale de crimes de guerre, et d'accéder rapidement et sans réserve aux futures demandes de coopération de la Cour pénale internationale. Il ne faut pas oublier non plus que les négociations ont toujours eu pour objectif de faire, en fin de compte, de la Cour pénale internationale une instance presque universellement reconnue. Lors de l'application du Statut de Rome (un instrument fort complexe), l'«appui technique » d'experts gouvernementaux ou non gouvernementaux peut également se révéler utile. Il importe dès lors de veiller à ce que les Etats-Unis ne s'opposent pas directement au bon fonctionnement de la Cour, comme prévoit de le faire la législation soumise au Congrès américain. ${ }^{129}$

Pour relever ces différents défis, il est plus que souhaitable que la Suisse continue de participer de manière constructive à l'instauration d'une Cour pénale forte et indépendante.

\section{QUELQUES OUVRAGES SUR LA COUR PÉNALE INTERNATIONALE (CPI)}

Blanke Hermann J. et Molitor Claus, «Der Internationale Strafgerichtshof », Archiv des Völkerrechts, 2001 , p. 142.

Caflisch Lucius, «Der neue Internationale Strafgerichtshof: ein Instrument zur Durchsetzung des humanitären Völkerrechts und der Menschenrechte», Liechtensteinische Juristen-Zeitung 1, 1999.

Cassese Antonio (ed.), International Criminal Law: A Commentary on the Rome Statute for an International Criminal Court, vol. 1-3, à paraître.

Henzelin Marc, «La Cour pénale internationale: organe supranational ou otage des Etats?», Schweizerische Zeitschrift für Strafrecht, 2001, p. 221.

Lee Roy S. (ed.), The International Criminal Court: The Making of the Rome Statute - Issues, Negotiations, Results, The Hague; Boston: Kluwer Law International, 1999.

Schabas William A., An Introduction to the International Criminal Court, Cambridge (UK); New York: Cambridge University Press, 2001.

Triffterer Otto (ed.), Commentary on the Rome Statute of the International Criminal Court: Observers' Notes, Article by Article, Baden-Baden: Nomos, 1999.

Vouilloz Madeleine, «La Cour pénale internationale», Aktuelle Juristische Praxis, 2000, p. 821.

\section{SITES INTERNET}

Site de la Coalition internationale des ONG sur la CPI : <www.iccnow.org/html/french.htm>.

Site du Conseil de l'Europe sur la CPI: <www.legal.coe.int/criminal/icc>.

Site de l'ONU sur la CPI: <www.un.org/law/icc/index.html>.

Université de Chicago, bibliographie et ressources sur la CPI sur Internet et sur papier: <www.lib.uchicago.edu/ llou/icc.html>.

\section{RATIFICATION ET APPLICATION PAR LA SUISSE}

Arrêté fédéral du 22 juin 2001 relatif à l'approbation du Statut de Rome de la Cour pénale internationale, FF 2001, pp. 2801 sqq., <www.admin.ch/ch/f/ff/2001/2801.pdf>.

Débat parlementaire, BO CN 2001, pp. 156-164 et 954-955 ainsi que BO CE 2001, pp. 465-469 et 475.

EDA, Direktion für Völkerrecht, Zusammenfassung der Vernehmlassungsergebnisse vom 15. November 2000, Römer Statut des Internationalen Strafgerichtshofs, Bundesgesetz über die Zusammenarbeit mit dem Internationalen Strafgerichtshof und Revision des Strafrechts.

129. Les projets de lois concernés sont connus sous le nom d'«American Servicemembers Protection Act ». Voir à ce sujet les liens mis à jour sur le site <www.iccnow.org $>$. 
Message du Conseil fédéral du 15 novembre 2000 relatif au Statut de Rome de la Cour pénale internationale, à la loi fédérale sur la coopération avec la Cour pénale internationale ainsi qu'à une révision du droit pénal, FF 2001, pp. 359 sqq., <www.admin.ch/ch/f/ff/2001/359.pdf>.

Loi fédérale du 22 juin 2001 portant modification du code pénal et du code pénal militaire (Infractions aux dispositions sur l'administration de la justice devant les tribunaux internationaux), FF 2001, pp. 2768 sqq., <www.admin.ch/ch/f/ff/2001/2768.pdf>.

Loi fédérale du 22 juin 2001 sur la coopération avec la Cour pénale internationale (LCPI), FF 2001, pp. 2748 sqq., <www.admin.ch/ch/f/ff/2001/2748.pdf>.

Statut de Rome de la Cour pénale internationale du 17 juillet 1998, UN Doc. A/CONF.183/9*, FF 2001, pp. 561 sqq., <www.admin.ch/ch/f/ff/2001/561.pdf>.

\section{RATIFICATION ET APPLICATION PAR LA SUISSE, SOURCES}

Cottier Michael, «Verfassungsrechtliche Aspekte der schweizerischen Ratifizierung des Römer Statuts », Schweizerische Zeitschrift für Strafrecht (à paraître).

Cottier Michael, «The Case of Switzerland», in Kress Claus et Lattanzi Flavia (Eds.), The Rome Statute and Domestic Legal Orders, vol. I, General Aspects and Constitutional Issues, Baden-Baden: Nomos, 2000, pp. 219 sqq. 